\title{
Dendritic Spine Loss and Chronic White Matter Inflammation in a Mouse Model of Highly Repetitive Head Trauma
}

\author{
Charisse N. Winston, * Anastasia Noël, ${ }^{\dagger}$ Aidan Neustadtl, ${ }^{*}$ Maia Parsadanian, ${ }^{*}$ David J. Barton, ${ }^{*}$ Deepa Chellappa, *
} Tiffany E. Wilkins, ${ }^{*}$ Andrew D. Alikhani, ${ }^{*}$ David N. Zapple, ${ }^{*}$ Sonia Villapol, ${ }^{*}$ Emmanuel Planel, ${ }^{\dagger \dagger}$ and Mark P. Burns ${ }^{*}$

\begin{abstract}
From the Laboratory for Brain Injury and Dementia, * Department of Neuroscience, Georgetown University Medical Center, Washington, District of Columbia; the Department of Psychiatry and Neurosciences, ${ }^{\dagger}$ Université Laval, Quebec City, Quebec, Canada; and the Research Center of CHU of Québec, Neurosciences, ${ }^{\ddagger}$ Quebec, Canada
\end{abstract}

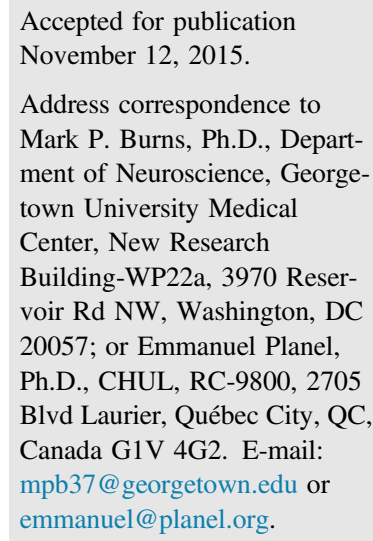

\begin{abstract}
Mild traumatic brain injury (mTBI) is an emerging risk for chronic behavioral, cognitive, and neurodegenerative conditions. Athletes absorb several hundred mTBIs each year; however, rodent models of repeat $\mathrm{mTBI}$ (rmTBI) are often limited to impacts in the single digits. Herein, we describe the effects of 30 rmTBIs, examining structural and pathological changes in mice up to 365 days after injury. We found that single mTBI causes a brief loss of consciousness and a transient reduction in dendritic spines, reflecting a loss of excitatory synapses. Single mTBI does not cause axonal injury, neuroinflammation, or cell death in the gray or white matter. Thirty rmTBIs with a 1-day interval between each mTBI do not cause dendritic spine loss; however, when the interinjury interval is increased to 7 days, dendritic spine loss is reinstated. Thirty rmTBIs cause white matter pathology characterized by positive silver and Fluoro-Jade B staining, and microglial proliferation and activation. This pathology continues to develop through 60 days, and is still apparent at 365 days, after injury. However, rmTBIs did not increase $\beta$-amyloid levels or tau phosphorylation in the $3 \times \mathrm{Tg}-\mathrm{AD}$ mouse model of Alzheimer disease. Our data reveal that single mTBI causes a transient loss of synapses, but that rmTBIs habituate to repetitive injury within a short time period. rmTBI causes the development of progressive white matter pathology that continues for months after the final impact. (Am J Pathol 2016, 186: 552-567; http://dx.doi.org/ 10.1016/j.ajpath.2015.11.006)
\end{abstract}

Athletes participating in contact sports are at high risk of exposure to large numbers of concussive and subconcussive mild traumatic brain injuries (mTBIs). Recent studies using head impact telemetry systems have begun to reveal how many head impacts an individual football player can receive in the process of playing his or her sport. In a study of high school football players, the number of helmet impacts $>20 \mathrm{~g}$ recorded in a single season ranged from a low of 226 (average, 4.7 per session) to a high of 1855 (average, 38.6 per session). ${ }^{1}$ Most of these impacts do not result in the clinical diagnosis of a concussion; however, it is not known if the cumulative effects of these impacts can result in increased damage to the brain.

mTBI has been extensively modeled in mice and rats. ${ }^{2}$ Most of these rodent models use fewer than five mTBIs, and report adverse events, including intracerebral bleeding, skull fractures, severe axonal injury, neuronal cell death, and increased mortality. ${ }^{3-8}$ These adverse

\footnotetext{
Supported by Georgetown University's Neural Injury and Plasticity Training Program grant T32NS041218, supported by the NIH (C.N.W.; principal investigators Dr. Jean Wrathall and Dr. Kathleen Maguire-Zeiss); the National Institute of Neurological Disorders and Stroke grant R01 NS067417 (M.P.B.); a Promote Diversity in Health-Related Research supplement (M.P.B.); a donation from K.P.B. Corporation (M.P.B.); Alzheimer Society of Canada postdoctoral awards (An.N.); the Canadian Institute of Health Research grants MOP-106423 and PCN-102993 (E.P.); Fonds de Recherche en Santé du Québec grants 16205 and 20048 (E.P.); and the Natural Sciences and Engineering Research Council of Canada grant 354722 (E.P.).

The funders had no role in the study design, data collection and analysis, decision to publish, or preparation of the manuscript

Disclosures: None declared.
} 
events prevent the scaling up of these animal models to reproduce the highly repetitive mTBI seen in impact sports. It is also unlikely that the severity of injury occurs with sports mTBI on a regular basis.

Repeat mTBI (rmTBI) is a risk factor for the development of chronic traumatic encephalopathy (CTE), a chronic neurodegenerative disease most often reported in boxers and football players. ${ }^{9,10}$ This disease is associated primarily with the buildup of neurofibrillary tangles of hyperphosphorylated tau throughout the brain; however, $52 \%$ of cases also present with diffuse amyloid- $\beta$ (A $\beta)$ deposits. ${ }^{11}$ There has been difficulty reproducing tau pathology in rodents after rmTBI, and to date the only study that has seen a chronic (21 days after TBI) increase in hyperphosphorylated tau after rmTBI has required the use of aged tau transgenic mice to observe an effect. ${ }^{12}$

In this study, we examine changes to the neuronal structure and brain pathology after a single mTBI or rmTBI. We are especially interested in changes that can occur after mTBI that may explain the changes in brain function after concussion. Herein, we characterize a new model of mTBI, determining the effects of a single mTBI, and up to $30 \times \mathrm{rmTBI}$, in $\mathrm{C} 57 \mathrm{~B} 1 / 6$ mice. We establish the effect of a 60- and 365-day period of convalescence on pathology, and the effect of increasing the interinjury interval from 1 to 7 days. Because the cumulative effects of rmTBI may cause the development of CTE in humans, and a recent study showed that 52\% of CTE brains have both amyloid and tau pathology, ${ }^{11}$ we also explore the effects of rmTBI on concurrent amyloid and tau pathology in a mouse model of Alzheimer disease $(3 \times \mathrm{Tg}-\mathrm{AD})$ that develops both types of pathology.

\section{Materials and Methods}

This study was performed in strict accordance with the recommendations in the Guide for the Care and Use of Laboratory Animals ${ }^{13}$ of the NIH. The protocol was approved by the Institutional Animal Care and Use Committee at Georgetown University (Washington, DC).

\section{mTBI Procedure}

The device used for these experiments has been previously published as a diffuse TBI model for rats, ${ }^{14,15}$ with modifications for use in mice (Figure 1A). A Teflon impactor tip, $10 \mathrm{~mm}$ in diameter, was driven by a high-velocity pneumatic impactor that was targeted to contact directly onto the top of the mouse head. The mouse head was supported by a molded, gel-filled base (HandStands, Salt Lake City, UT), which also acts to decelerate the head after impact (Figure 1B). The middle diameter of the gel mold is 170 $\mathrm{mm}$, and its compressibility is approximately $64 \mathrm{kPa} / \mathrm{mm}$. Speed, head deflection depth, and surface dwell time can all be individually adjusted, and each impact is monitored with a PowerLab System (Stoelting, Wood Dakem, IL) for consistency and reproducibility. The device has a piston with a stroke length of $101 \mathrm{~mm}$ and a bore diameter of $27.025 \mathrm{~mm}$, and for these experiments, we used $861.85 \mathrm{kPa}$ of pressure, resulting in a force output stroke of $494 \mathrm{~N}$. With a $10-\mathrm{mm}$ diameter Teflon tip at the end of the impactor, the impact energy delivered to the mouse head was $6.3 \mathrm{~N} / \mathrm{mm}^{2}$. The impactor tip had an end velocity of $2.35 \mathrm{~m} / \mathrm{second}$, and the dwell time was 31.5 milliseconds (Figure 1, C and D).

Mice were anesthetized with 3\% isoflurane in oxygen for 120 seconds in an induction chamber, and then transferred to
A
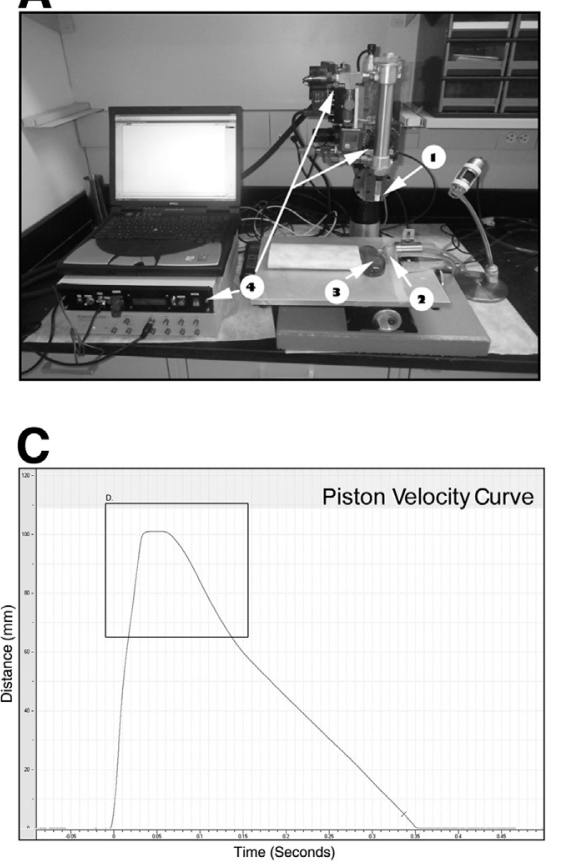

B
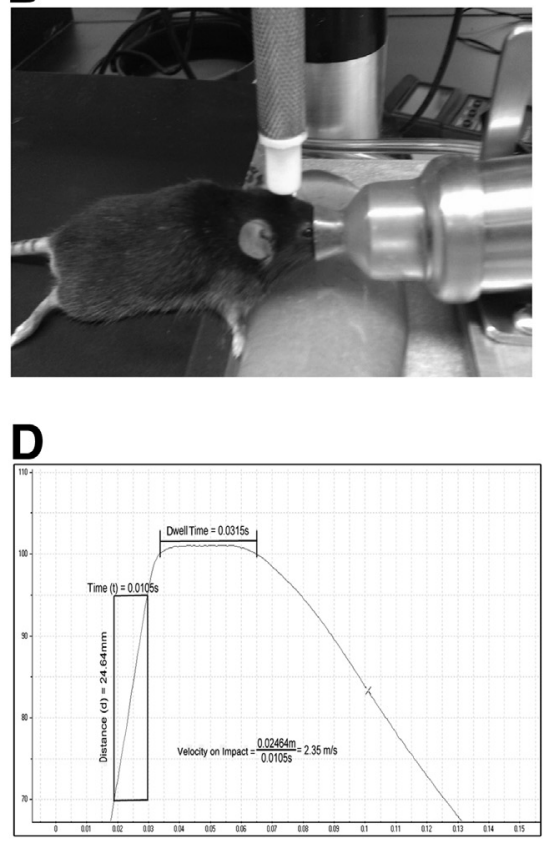

Figure 1 A mouse model of mild traumatic brain injury (mTBI). A: Image of the pneumatic piston and controls for the mTBI device. Highlighted are the following: (1) 10-mm Teflon impactor tip, (2) pliant anesthesia nose cone, (3) gel head-rest; and (4) microprocessor-controlled valves to regulate piston velocity and dwell time. B: An image of the mouse in the apparatus. C: Instant feedback monitoring provides information on piston velocity and dwell time. The enlarged inset (D) shows that at the time of impact the piston had a velocity on impact of $2.35 \mathrm{~m} / \mathrm{second}$ and a maximum dwell time of 31.5 milliseconds. 
the injury device, where they continued breathing anesthetic through a pliable, nonfixed nose cone. There was no skin deflection or surgery of any kind. The mouse head was positioned on the gel pad so that the flat surface of the skull was presented perpendicular to the impactor tip and the ears were held away from the impact site with tape. The impactor tip was lowered to the surface of the mouse head, retracted, and manually dialed down to the required deflection depth. After impact, the mice were removed from isoflurane and placed on their backs. The latency to return of righting reflex was determined and used as the primary measure of injury severity. For pathology and behavioral studies in C57Bl/6 mice, the animals were impacted once a day, 5 days a week, for 30 impacts. Mice were euthanized at 1, 30, 60, or 365 days after the final impact. To determine the effects of an extended interinjury interval on C57Bl/6 mice, animals received one impact per week for 30 weeks. Sham mice received similar handling and anesthesia, but received no impact.

\section{Mice}

C57B1/6J male mice (Jackson Laboratories, Bar Harbor, MA) were used for all experiments, except the amyloid/tau analysis, which used 3xTg-AD mice. C57Bl/6 mice were aged from 3 to 5 months at the time of injury onset, except for a 12-month-old cohort that was used to determine the interaction of age and $\mathrm{mTBI}$ on dendritic spines.

The 18-month-old male $3 \times \mathrm{Tg}$-AD mice, ${ }^{16}$ expressing human amyloid precursor protein (APP; K670M/N671L), human tau (P301L), and PS-1 (M146V) (knock-in) mutant genes, were used from the colony previously characterized at Georgetown University. ${ }^{17}$ These mice were aged to 18 months, because that is the age that amyloid plaque deposition and tau pathology begin to appear in this colony. Mice were housed at the Georgetown University animal facility in a temperaturecontrolled room at $22^{\circ} \mathrm{C}$ and were kept on a 12-hour light/12hour dark cycle. Food and water were available ad libitum.

\section{Golgi Staining}

For detailed characterization of neuronal processes and spines, we performed Golgi staining using the FD Rapid Golgi Stain Kit (FD NeuroTechnologies, Ellicott City, MD), as previously reported. ${ }^{18}$ Bright-field microscopy images of pyramidal neurons in layers II/III of the cortex were captured, and the number of dendritic spines on basal shaft (BS) and apical oblique (AO) dendrites was quantified. BS dendrites project directly off the cell soma, and our counts incorporated dendritic spines along a $20-\mu \mathrm{m}$ section of the shaft between 30 and $100 \mu \mathrm{m}$ away from the soma. AO dendrites project off the apical dendrite, and our counts only incorporated primary $\mathrm{AO}$ dendrites. We counted spines in a $20-\mu \mathrm{m}$ section of the primary AO. Different neurons were used to quantify AO and BS segments of healthy pyramidal neurons of cortical layers II/III. Slides and resultant images were coded, and dendritic spines were counted in a blinded manner (C.N.W., A.Ne., D.B., D.C., T.E.W., A.D.A.) using ImageJ software version 1.46a (NIH, Bethesda, MD; http:// imagej.nih.gov/ij). The group mouse and neuron numbers for each experiment are noted in the figure legends.

For Sholl analysis, images of Golgi-stained pyramidal neurons were overlaid with concentric circles, consisting of a $10-\mu \mathrm{m}$ radius between each circle. The concentric circles spanned from 0 to $70 \mu \mathrm{m}$, with a radial interval of $10 \mu \mathrm{m}$ between each circle. The center point of the circles was superimposed over the cell body of previously acquired Golgi-stained neurons, and the number of $\mathrm{AO}$ and $\mathrm{BS}$ dendrites crossing each circle was manually counted and plotted as number of crossings against distance from soma.

\section{Immunohistochemistry and Staining}

Mice were anesthetized and transcardially perfused with phosphate-buffered saline (PBS), and brains were drop fixed in $4 \%$ paraformaldehyde overnight before cryoprotection in $30 \%$ sucrose for 48 hours. Brains were cut into sections (40 $\mu \mathrm{m}$ thick) using a microtome and were stored free floating in cryoprotectant solution. Before immunostaining, sections were incubated in $0.3 \% \mathrm{H}_{2} \mathrm{O}_{2}$ and blocked with $3 \%$ normal goat serum in PBS with $0.25 \%$ Triton X-100, and incubated in PBS with $0.25 \%$ Triton X-100 and $1 \%$ normal goat serum with primary antibody. The following primary antibodies used included rabbit polyclonal anti-Iba-1 (1:5000; Wako Chemicals, Richmond, VA; catalog number 019-19741), mouse monoclonal anti-CD68 (1:200; Serotec, Raleigh, NC; catalog number MCA1957T), rabbit polyclonal anti-APP (1:1000; Invitrogen, Camarillo, CA; catalog number 36-6900), and rabbit polyclonal anti-glial fibrillary acidic protein (1:500; Dako, Carpinteria, CA; catalog number Z-0334). After washes in PBS, sections were incubated in biotinylated goat anti-rabbit or antimouse secondary antibodies (1:2000; Vector Laboratories, Burlingame, CA; catalog number BA-100) in PBS with $0.25 \%$ Triton X-100, followed by the Vectastain avidin/biotinylated enzyme complex kit (1:400; Vector Laboratories; catalog number PK-6100) and 3,3'-diaminobenzidine (Sigma-Aldrich, St. Louis, MO) substrate to visualize primary antibodies.

For Fluoro-Jade B, floating sections were hydrated in distilled water and incubated in a solution of $0.06 \%$ potassium permanganate (Sigma-Aldrich) for 10 minutes. After washing, the sections were incubated in a $0.0004 \%$ solution of Fluoro-Jade B for 20 minutes. Brain sections were rinsed in distilled water, dried, and cleared in xylene before mounting with Fluoro-Gel with Tris Buffer (Electron Microscopy Sciences, Hatfield, PA). For silver staining, coronal sections were washed in distilled water and stained using a modified procedure of DeOlmos-Ingram cupric silver technique, as previously reported. ${ }^{19}$

\section{Quantitative and Densitometry Analysis}

Histological sections were assessed for staining in the regions covering the entire optic tract ( -2.18 to $-2.70 \mathrm{~mm}$ Bregma). 
Every fourth coronal section of the optic tract was selected, yielding at least four sections collected per animal. From each section, three distinct fields within the optic tract were randomly selected and four images of sequential optical $z$ sections were obtained from each field. Images from each field were combined into a single overlay image, and Iba-1-positive cells were counted using the overlay. Helicon Focus software version 3.2 (HeliconSoft, Kharkov, Ukraine) was used for three-dimensional reconstruction of $z$ section thickness. The total number of Iba-1-positive cells was expressed per $\mathrm{mm}^{2}$. Bushy microglial cells were identified by short thick processes, few branches, and larger cell body volume. ${ }^{20}$ For phenotypic analysis of the microglia population, the expression level of microglial cells containing this bushy phenotype was quantified as the percentage of total number of Iba-1-positive cells.

For densitometry analysis, a total of three sections per brain of silver-stained images were captured using a $20 \times$ objective. These images were converted to grayscale with background subtraction, and the mean gray levels were measured with ImageJ software. Images were taken on an Olympus BX51 microscope (Olympus America, Center Valley, PA), using Olympus CellSens software version 1.5. Only general adjustments of contrast and brightness were made using Adobe Photoshop CS5 for Macintosh (Adobe Systems, San Jose, CA). The images were not otherwise manipulated.

\section{Western Blot Analysis and Enzyme-Linked Immunosorbent Assay}

To avoid transient artifactual changes in tau phosphorylation, $3 \times \mathrm{Tg}-\mathrm{AD}$ mice were sacrificed by decapitation without anesthesia, ${ }^{21}$ and the brain was rapidly dissected on ice. Samples were snap frozen and stored at $-80^{\circ} \mathrm{C}$. Frozen tissues were homogenized in radioimmunoprecipitation assay buffer $[50 \mathrm{mmol} / \mathrm{L}$ Tris- $\mathrm{HCl}(\mathrm{pH} 7.4), 1 \mathrm{mmol} / \mathrm{L}$ EDTA, $150 \mathrm{mmol} / \mathrm{L} \mathrm{NaCl}, 1 \%$ Nonidet $\mathrm{P}-40,0.25 \%$ $\mathrm{C}_{24} \mathrm{H}_{39} \mathrm{NaO}_{4}, 1 \mathrm{mmol} / \mathrm{L} \mathrm{NaVO}_{3}, 1 \mathrm{mmol} / \mathrm{L} \mathrm{NaF}, 1 \mathrm{mmol} / \mathrm{L}$ phenylmethylsulfonyl fluoride, and $10 \mu \mathrm{g} / \mathrm{mL}$ protease inhibitor cocktail (Sigma-Aldrich)] and centrifuged at $135,000 \times g$ for 45 minutes at $4^{\circ} \mathrm{C}$. The radioimmunoprecipitation assay-insoluble pellet from cortical homogenates was resuspended in one volume of $70 \%$ formic acid, sonicated, and centrifuged at 23,500 $\times g$ for 15 minutes at $4{ }^{\circ} \mathrm{C}$. The supernatant was collected (formic acid fraction containing insoluble proteins) and neutralized in 20 volumes of neutralization buffer containing $1 \mathrm{~mol} / \mathrm{L}$ of Tris base and $0.5 \mathrm{~mol} / \mathrm{L}$ of $\mathrm{Na}_{2} \mathrm{PO}_{4}$. The resulting supernatants were collected and analyzed for protein content using bicinchoninic acid assay kit (Thermo Fisher Scientific, Inc., Logan, UT). Samples were stored at $-80^{\circ} \mathrm{C}$ until processing.

For Western blot analysis, samples were prepared as previously described. ${ }^{22}$ Proteins (5 to $10 \mu \mathrm{g}$ ) were separated on SDS-PAGE gels, blotted onto nitrocellulose membranes, and blocked 1 hour at room temperature with 5\% nonfat dry milk in PBS containing $0.1 \%$ Tween 20. Membranes were probed with primary antibodies (listed below) diluted in SuperBlock blocking buffer (Thermo Fisher Scientific, Rockford, IL), washed, and incubated for 1 hour at room temperature with the corresponding horseradish peroxidase-linked secondary antibody. For tau analysis, a secondary antibody directed against light chain of immunoglobulins was used to detect monoclonal primary antibodies to avoid non-specific signals coming from the heavy chains of Igs. ${ }^{22}$ Membranes were revealed by enhanced chemiluminescence (ECL Plus; GE Healthcare Biosciences, Piscataway, NJ) in a Fujifilm LAS4000 imaging system (Fujifilm USA, Valhalla, NY). Densitometric analyses were performed with Image Gauge analysis software version 3.0 (Fujifilm USA). Primary antibodies (from Thermo Fisher Scientific unless otherwise specified) used were AT270 against pTauThr181 (number MN1050), CP13 against pTauSer202 (Dr. Peter Davies, Litwin-Zucker Research Center for The Study of Alzheimer Disease and Memory Disorders, Manhasset, NY), Thr205 (number 44738G), AT8 against pTauSer202/ Thr205 (number MN1020), Tau-1 against nonpTauSer195/Ser198/Ser199/Ser202 (number MAB3420; Millipore, Temecula, CA), Ser199 (number 44734G), AT180 against pTauThr231 (number MN1040), PHF-1 against pTauSer396/Ser404 (Dr. Peter Davies), Ser422 (number AB79415; Abcam, Cambridge, MA), total tau against the C-terminus of tau (number A0024; Dako, Glostrup, Denmark), CP27 against human tau (Dr. Peter Davies), and $\beta$-actin (number WH00000060M1; Sigma-Aldrich).

Human $A \beta 40$ was quantified by enzyme-linked immunosorbent assay (Invitrogen, Carlsbad, CA), as previously described. $^{23}$ This kit uses a neo-epitope-specific antibody to specifically detect human $\mathrm{A} \beta 40$.

\section{Behavioral Analysis}

Behavioral analysis was performed to test motor ability, anxiety, and cognitive function.

\section{Rotarod Test}

The rotarod test is a test of motor function and consists of a mouse walking on a rotating beam, which accelerates from 4 to $40 \mathrm{rpm}$ over 300 seconds. Mice were exposed to the rotarod test for two trials on the day before the first injury, and then their postinjury performance was tested 1 and 365 days after injury. Two trials were performed on each test day, and the average time to fall from the rotating beam was measured in seconds.

\section{Morris Water Maze}

Spatial learning and memory deficits were evaluated starting 7 and 365 days after injury, using the Morris water maze paradigm, as described previously. ${ }^{24}$ Briefly, the water maze apparatus consisted of a 4-foot diameter pool (San Diego Instruments, San Diego, CA) filled with water maintained at 
$20^{\circ} \mathrm{C}$ and made opaque using white paint. Extramaze visual cues were hung on the walls surrounding the pool, and a hidden platform (4 inches in diameter) was submerged $1 \mathrm{~cm}$ below the surface of the water. Initial training was started 1 week and 1 year after injury and consisted of four trials per day. Mice were introduced into the pool using one of four entry points, with each entry point used during the course of the day. The location of the platform remained constant throughout the entire training period. Mice were given 90 seconds to locate the platform and remained on the platform for 10 seconds before being removed. Mice that did not locate the platform within 90 seconds were placed onto the platform for 10 seconds before removal from the maze. Tracking software (Anymaze version 4.50; San Diego Instruments) was used to record latency to find the platform, swim speed, and swim path. On the fifth day of testing, a probe trial was conducted in which the platform was removed and the time spent in each quadrant was recorded over one 90 -second trial.

\section{Elevated Plus Maze}

The elevated plus maze was used to assay anxiety-like behavior 21 days after injury, as previously described, ${ }^{24}$ with modifications. The apparatus (San Diego Instruments) consists of a 26-inch long cross-shaped platform made of nonporous white plastic and elevated 15 inches above the ground. One set of arms is enclosed with walls (closed arms), and one set is exposed (open arms). A spotlight was positioned overhead to provide 750-lux illumination over the center of the maze and the exposed open arms. Mice were placed at the center junction of the maze, facing an open arm, and given 5 minutes to explore. The number of entries into each arm, the time spent in each arm, and the total distance traveled in the maze (and in each individual arm) were tracked using the video camera positioned over the maze and analyzed using Anymaze software. The software tracked the center point of the mouse body, and mice were considered to have entered an arm when their center point crossed into the arm.

\section{Statistical Analysis}

Data were analyzed using a one-way analysis of variance, followed by post hoc analysis with Bonferroni multiple comparisons test, and presented as the means \pm SEM. All statistical tests were performed using GraphPad Prism software, version 5.0d (GraphPad Software, Inc., San Diego, CA), and $P<0.05$ was considered statistically significant.

\section{Results}

\section{Increasing the Depth of Head Deflection Results in} Graded LOC

Although loss of consciousness (LOC) is not a necessary component of mTBI in humans, the presence or absence of LOC is a useful tool in grading concussion severity in animal models. The return of the righting reflex time is an acute neurological evaluation of injury severity that we used to quantify the LOC after a single mTBI. For this procedure, all mice received a total of 180 seconds of $3 \%$ isoflurane in oxygen. Because of this, all mice, including shams, had a period of LOC after withdrawal of anesthesia. We found that sham mice had an average LOC of 29.9 seconds. Inducing mTBI with a head deflection setting of $5 \mathrm{~mm}$ did not result in any change to the LOC time (31.0 seconds). When the head deflection setting was increased to $7.5 \mathrm{~mm}$, the LOC increased to 53.4 seconds $(P<0.001$ versus sham and $5 \mathrm{~mm}$ ) (Figure 2A). We also piloted a $10-\mathrm{mm}$ head deflection, and the LOC was significantly increased to 330.4 seconds in a few animals. This was associated with an increase in what we considered to be adverse events, including prolonged apnea and LOC, and a single case of skull fracture. The results of our injury severity experiment
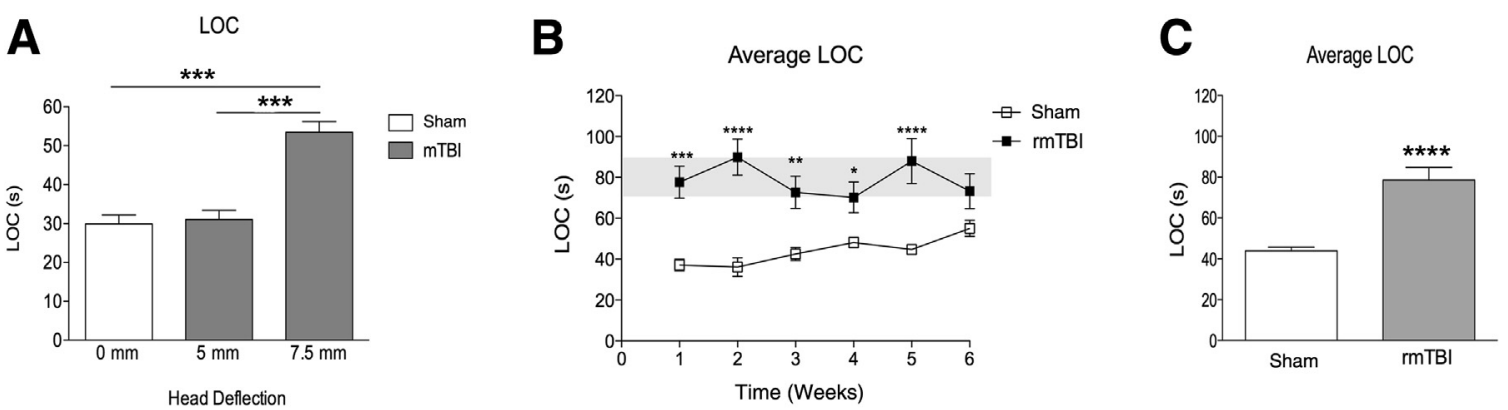

Figure 2 Loss of consciousness (LOC) after single and repeat mild traumatic brain injury (rmTBI). A: LOC time in seconds for mice exposed to isoflurane, followed by a head deflection of 0,5 , and $7.5 \mathrm{~mm}$. LOC was determined by the time for the righting reflex to return after impact. One way analysis of variance with Bonferroni post hoc test was used. B: The average weekly LOC for 30 rmTBI (over 6 weeks) mice. Each week contains the average LOC of five time points to control for daily variability. The gray box highlights that there is no appreciable decrease in the LOC duration in rmTBI mice from week 1 through week 6 . Two-way repeated-measures analysis of variance with Bonferroni post hoc test. C: The average LOC of all 30 time points for the sham versus repeat mTBI groups. Unpaired $t$-test was used. ${ }^{*} P<0.05,{ }^{* *} P<0.01,{ }^{* * *} P<0.001$, and ${ }^{* * * *} P<0.0001$. $n=9$ to $11(\mathbf{A}) ; n=9$ (B and $\mathbf{C})$. 
showed that the 7.5-mm head deflection setting provided us with the lowest identifiable and quantifiable LOC in the absence of any discernable injury to the mice. Because the overall goal of this study was to develop and characterize this device as a preclinical model of repetitive injury, we selected the $7.5-\mathrm{mm}$ head deflection setting for all subsequent experiments.

\section{The Duration of LOC Remains Static after rmTBI}

The effect of rmTBI on the duration of LOC is difficult to determine in humans, because factors such as impact force and impact location vary from one impact to the next. In our model, we were able to deliver an almost identical mTBI on a daily basis, and as a result, we wanted to quantify LOC duration after rmTBI. In the anesthesia alone sham group, we found that the day-to-day LOC could fluctuate from a high of $62.7 \pm 12.5$ seconds on day 26 to a low of $25 \pm 2.3$ seconds on day 22. To account for these fluctuations in LOC, we averaged the readings from each 5-day week so that we could better assess the effect of rmTBI on LOC (Figure 2B). A repeated-measures 2-way analysis of variance revealed a significant effect of injury $\left(\mathrm{F}_{1,16}=29.47\right.$, $P<0.0001$ ), but no effect of time. There was a significant interaction between time and injury $\left(\mathrm{F}_{5,80}=3.38\right.$, $P<0.01)$. Post hoc analysis revealed that rmTBI mice had significantly elevated LOC at weeks 1 through $5(P<0.05)$ (Figure 2B), but not week 6. During the entire study, the average LOC for sham mice was $44.0 \pm 1.8$ seconds; and for rmTBI mice, $78.6 \pm 6.1$ seconds $(P<0.0001)$ (Figure 2C).

\section{Neuronal Architecture Changes after mTBI}

After a single 7.5-mm mTBI, mice were sacrificed at various time points up to 3 days after injury, and we visualized individual neurons using Golgi staining. We found no evidence of unhealthy neurons after a single mTBI that would have been indicated by Golgi-positive cells displaying dendritic dystrophy, dendritic blebbing, or atrophic cell bodies. Our blinded spine analysis (C.N.W., A.Ne., D.B., D.C., T.E.W., A.D.A) found that mTBI caused a $13 \%$ decrease in the number of AO dendritic spines at 1 day $(P<0.01$ versus sham $)$. This was followed by a $25 \%$ increase in spine number by 3 days after injury, resulting in a $12 \%$ increase in spines compared with sham mice $(P<0.05$ versus sham) (Figure 3A). BS dendritic spines were not significantly affected by mTBI (data not shown). Dendritic complexity was also unaffected, with Sholl analysis revealing no differences in neuronal arborization between sham and mTBI mice at 1 day after injury (Figure 3B).

We repeated our study using 12-month-old C57B1/6 mice. We found that a single $(7.5-\mathrm{mm}) \mathrm{mTBI}$ resulted in a $29 \%$ reduction in AO dendritic spines at 1 day after injury $(P<0.001)$ (Figure 3C). There was a 13\% reduction in BS dendritic spines of aged mTBI mice, but this failed to reach significance $(P=0.06)$ (Figure 3C).
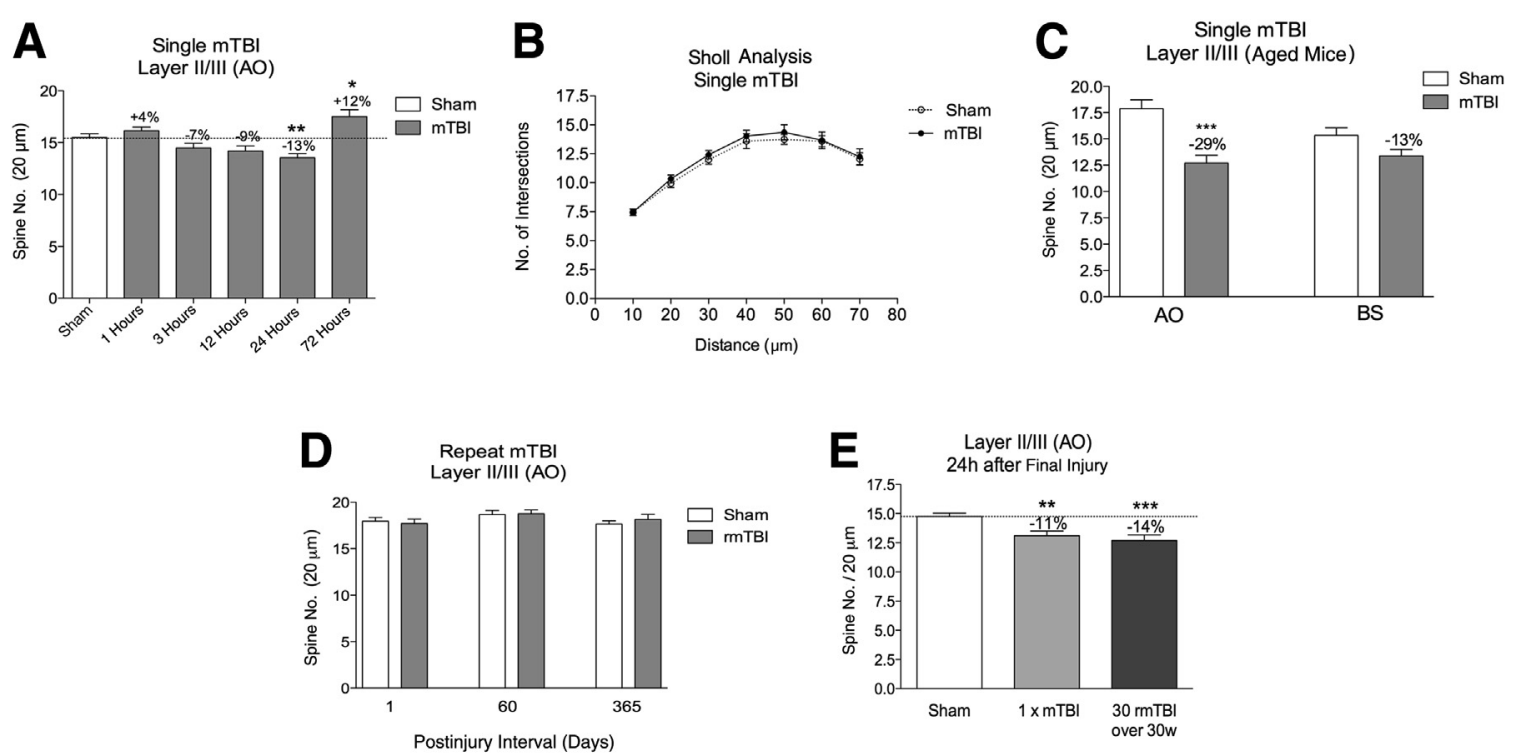

Figure 3 Single mild traumatic brain injury (mTBI) causes a transient decrease in dendritic spine number, and habituation to dendritic spine loss in repeat mTBI (rmTBI) mice is prevented by extending the interinjury interval. A: A single 7.5-mm mTBI causes a time-dependent, and transient, loss of apical oblique (A0) dendritic spines in the superficial layers of the parietal cortex. Results represent an average of 32 to 76 neurons per time point from three to six mice per group. One-way analysis of variance with Bonferroni post hoc test was used. B: mTBI has no impact on dendritic arborization at 24 hours after mTBI. C: The loss of A0 spines is more pronounced in 12-month-old C57Bl/6 mice at 24 hours after injury. D: There is no effect of 30 rmTBI (over 6 weeks) on dendritic spine numbers in layer II/III of the cortex at 1, 60, or 365 days after injury. E: Mice were exposed to either anesthesia once a week for 30 weeks (sham), anesthesia for 29 weeks, followed by a single mTBI $(1 \times \mathrm{mTBI})$, or mTBI once a week for 30 weeks ( $30 \mathrm{rmTBIs}$ over 30 weeks). Both single mTBI and $30 \mathrm{mTBIs}$ over 30

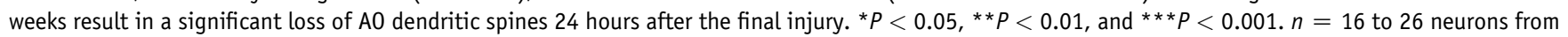
three mice in each group (C); $n=53$ to 60 neurons from five mice in each group (D). BS, basal shaft. 


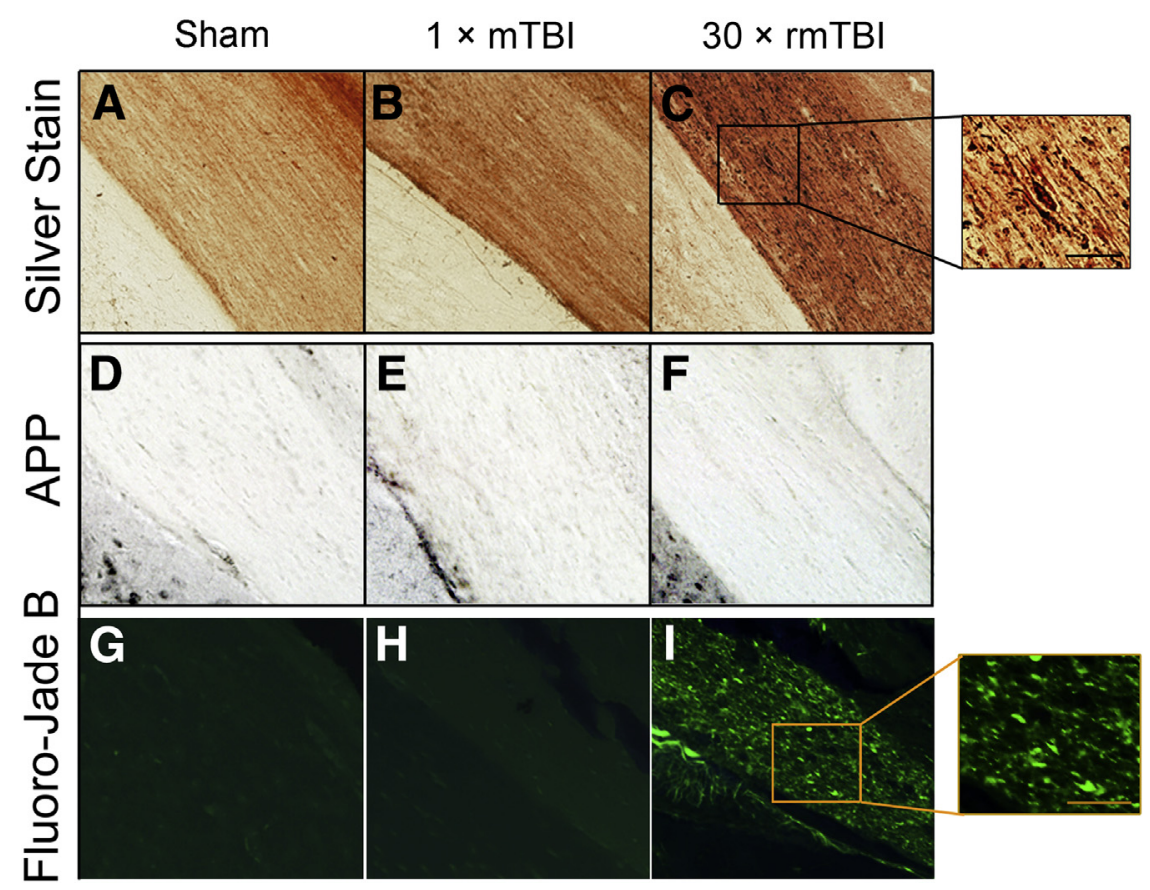

Figure 4 The effect of single and repeat mild traumatic brain injury (rmTBI) on degenerative markers in the optic tract. Representative images of silver stain $(\mathbf{A}-\mathbf{C})$, amyloid precursor protein (APP; $\mathbf{D}-\mathbf{F})$, and Fluoro-Jade B (G-I) staining in the optic tract of sham, single mTBI, and 30 rmTBI (over 6 weeks) mice. Enlarged silver and Fluoro-Jade B staining in the $30 \mathrm{rmTBI}$ mice demonstrating evidence of axonal abnormalities and degenerating cells. Scale bars: $50 \mu \mathrm{m}$ (A-F); $20 \mu \mathrm{m}$ (C and I, magnified panels).

To determine the effect of rmTBI, we exposed mice to 30 rmTBIs administered one per day, 5 days a week, for 6 weeks. Mice were euthanized 1, 60, or 365 days after injury with time-matched sham controls. We found no difference in dendritic spine numbers at any of the three time points (Figure 3D).

To assess if the lack of effect of rmTBI on dendritic spines is because of habituation, we extended the interinjury interval from 1 to 7 days. Mice received 30 mTBIs, one per week, for 30 weeks. As a positive control, we also exposed a cohort of mice to weekly anesthesia for 29 weeks with a single mTBI at week 30. Mice were euthanized 1 day after the final mTBI. We found that the reduction in synapses returned to $30 \times$ rmTBI mice when there was a 7-day interinjury period between impacts. Mice with a single mTBI had an $11 \%$ reduction in AO dendritic spines $(P<0.01$ versus sham $)$, and mice with $30 \times$ rmTBI over 30 weeks had a $14 \%$ reduction in $\mathrm{AO}$ dendritic spines $(P<0.001$ versus sham) (Figure $3 \mathrm{E})$.

\section{The Acute Effect of Single mTBI and rmTBI on Neuronal} Cell Death and Axonal Injury

To determine whether the 30 mTBIs (over 6 weeks) model causes axonal injury, we stained sections with the $\beta$ APP and silver stain. We did find evidence of axonal distress in discrete white matter tracts after $30 \times$ rmTBI (Figure 4). Strong positive silver staining (Figure 4, A-C) and Fluoro-Jade B-positive staining (Figure 4, G-I) were observed in the optic tract of rmTBI mice 1 day after the final injury, suggesting that the supporting cells of the optic tract were degenerating as a result of rmTBI. No APP staining was observed in the optic tract (Figure 4, D-F).
Although we saw occasional silver staining in the white matter tracts of the cerebellum of rmTBI mice, no other evidence of damaged white matter tracts, including the corpus callosum, internal capsule, or hippocampal fimbria, was observed. In addition, no evidence of cell death or axonal injury in the gray matter of the rmTBI brain, including the cortex, hippocampus, thalamus, or cerebellum (data not shown), was observed.

\section{The Acute Effect of Single mTBI and rmTBI on Brain Inflammation}

To detect changes in glial populations after single mTBI and rmTBI, we used glial fibrillary acidic protein as a marker of astrocytes, and Iba-1 and CD68 to probe for microglia/ macrophages. Once again, we found no detectable effect of a single mTBI on inflammatory markers 1 day after injury (Figure 5). However, we found increased immunoreactivity for both astrocytes and microglia in the optic tract after $30 \times$ rmTBI (over 6 weeks) (Figure 5). Iba-1- and CD-68-positive microglia were found extensively throughout the optic tract (Figure 5), with infiltration into the lateral geniculate nucleus of the thalamus (Figure 5).

\section{rmTBI Causes Chronic White Matter Pathology}

To study the effects of rmTBI on chronic pathology, mice were euthanized at 1, 60, and 365 days after final injury. We found a 21-fold increase in silver staining of the optic tract 1 day after the final injury compared to sham $(P<0.001)$ (Figure 6, A-F). At 60 days after injury, there was still a fourfold increase in silver staining in the optic tract, but this was significantly less than at 1 day after injury $(P<0.001)$ 


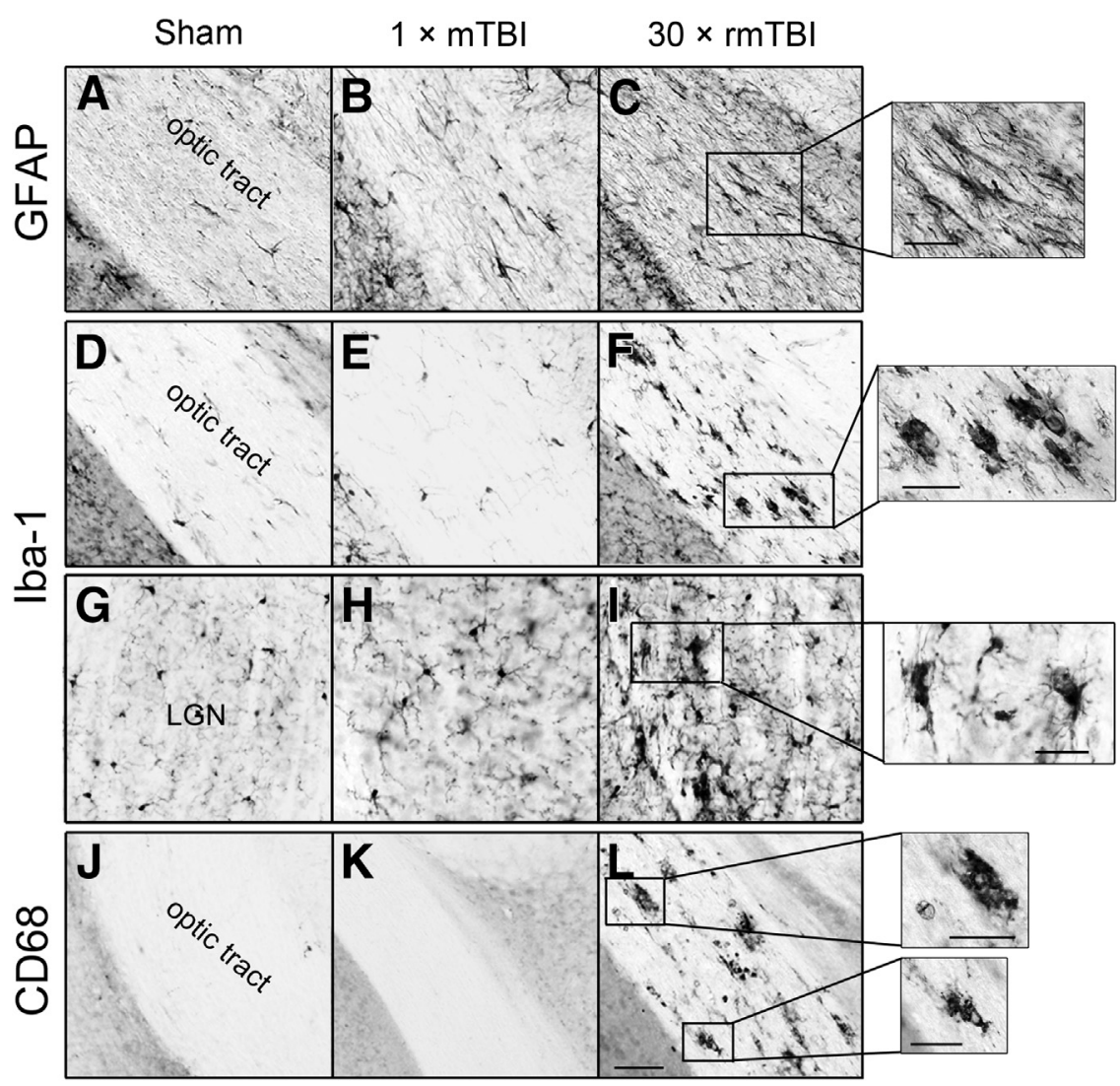

Figure 5 The effect of single and repeat mild traumatic brain injury (rmTBI) on inflammation in the optic tract and lateral geniculate nucleus (LGN). Representative images of glial fibrillary acidic protein (GFAP; A-C), Iba-1 (D-I), and CD68 (J-L) in the optic tract and LGN of sham, single mTBI, and 30 rmTBI (over 6 weeks) mice. Enlarged images demonstrating the morphology of GFAP-positive astrocytes, Iba-1, and CD68-positive microglia in 30 rmTBI mice at 1 day after the final injury. Scale bars: $50 \mu \mathrm{m}(\mathbf{A}-\mathbf{L}) ; 20 \mu \mathrm{m}$ (C, F, I, and $\mathbf{L}$, magnified panels).

(Figure 6, A-F). At 365 days after injury, there was little silver staining remaining (Figure 6, D-F).

We also quantified the number of Iba-1-positive cells, and the number of Iba-1-positive microglia with an enlarged, bushy phenotype (Figure 6, G-L). Quantification of the Iba-1-positive cells in the optic tract revealed a $206 \%$ increase in microglia 1 day after $30 \times$ rmTBI (over 6 weeks) $(P<0.001)$ (Figure 6, G-L), which continued to increase to $249 \%$ above sham levels at 60 days after injury $(P<0.001)$ (Figure 6, G-L). There were 49\% more Iba-1-positive cells in $30 \times$ rmTBI 60 days after injury compared with 1 day after injury $(P<0.001)$ (Figure $6, \mathrm{G}-\mathrm{L})$. The morphology of these cells also continued to develop because 60-day postinjury mice had $78 \%$ more microglia with a bushy phenotype compared with mice 1 day after injury $(P<0.001)$ (Figure 6, $\mathrm{G}-\mathrm{L}$ ). There were still significantly more Iba-1-positive microglia in the optic tract compared with sham mice 365 days after rmTBI $(P<0.01)$ (Figure 6, G-L); however, there were only a few bushy microglia remaining at this time point (Figure 6, G-L).

\section{The Effect of rmTBI on Behavior}

We tested acute and chronic behavioral changes in mice after $30 \times$ rmTBI (over 6 weeks). For motor function, we used the accelerating rotarod test and found that rmTBI mice were not impaired at 1 day after final injury. However, at 365 days after injury, the same mice showed a $20.9 \%$ reduction in the latency to fall from the rotarod $(P<0.05)$ (Figure 7A).

For learning and memory testing, we performed the Morris water maze. We found that rmTBI mice had no cognitive deficits at 7 or 365 days after injury in either the acquisition phase of the test (Figure 7, B and C) or the retention phase of the test (Figure 7, D and E). Both rmTBI and sham mice were able to find a visible platform with similar latencies, and we observed no difference in velocities between groups in the water maze.

For anxiety testing, we used the elevated plus maze. We found that rmTBI mice had no phenotypic changes at 6 months after injury, but we did observe a $46 \%$ decrease in the time spent in the open arm of the maze in the $30 \times$ rmTBI mice at 365 days after injury $(P<0.05)$, reflecting an increased anxiety phenotype in the repeat injury group many months after the final mTBI (Figure 7F).

\section{The Effect of rmTBI on Amyloid and Tau Pathology}

Because rmTBI has been implicated in the development of $\mathrm{AD}$ and $\mathrm{CTE}$, we wanted to examine the effects of rmTBI on amyloid and tau pathology. We used 18-monthold 3xTg-AD mice for these studies, and because of their advanced age, we limited them to 20 rmTBIs. We euthanized one cohort of sham and rmTBI mice 24 hours after the final injury and a second cohort 1 month after injury. 

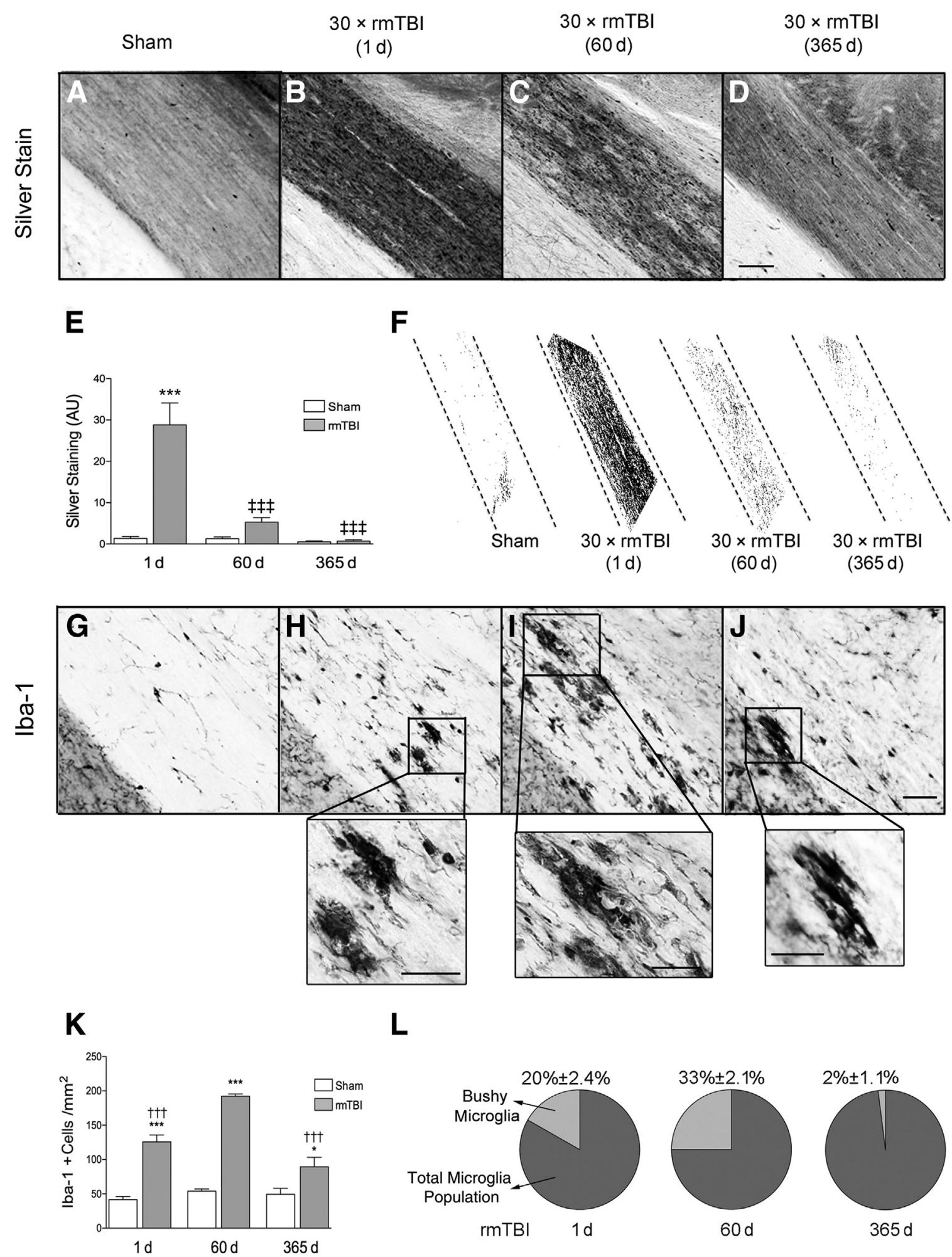

$\mathbf{L}$
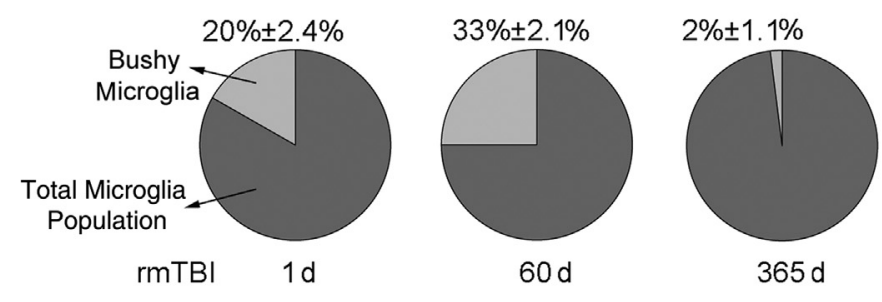

Figure 6 The effect of recovery time on optic tract pathology in repeat mild traumatic brain injury (rmTBI) mice. Silver stain pathology is absent in the optic tract of sham mice (A), but is present in $30 \mathrm{rmTBI}$ (over 6 weeks) mice at 1 day after the final injury (B). Silver is present 60 days after rmTBI (C), but resolves by 365 days after injury (D). Silver staining quantification of representative threshold images for each time point after injury (E) and sham optic tract $(\mathbf{F})$. There are no Iba1-positive microglia with activated morphology in the optic tract of sham mice (G), but both the total number of Iba-1 cells and the number of Iba-1 cells with a bushy morphology increase at 1 day (H), and continue to increase through 60 days after injury (I). J: Iba-1-positive cells remain elevated at 365 days after injury. $\mathbf{K}$ and $\mathbf{L}$ : Quantification of the Iba-1-positive microglial cells in the optic tract (K) and pie charts displayed as a percentage of bushy microglial cells of total Iba-1 population (L). ${ }^{*} P<0.05, * * * P<0.001$ versus time-matched sham; ${ }^{\dagger \dagger \dagger} P<0.001$ versus 60 days rmTBI; ${ }^{\ddagger \ddagger \ddagger} P<0.001 . n=5$ to 6 (E, $\mathbf{K}$, and $\left.\mathbf{L}\right)$. Scale bars: $50 \mu \mathrm{m}$ (A-D and $\left.\mathbf{G}-\mathbf{J}\right) ; 20 \mu \mathrm{m}(\mathbf{H}-\mathbf{J}$, magnified panels). $\mathrm{AU}$, arbitrary unit. 


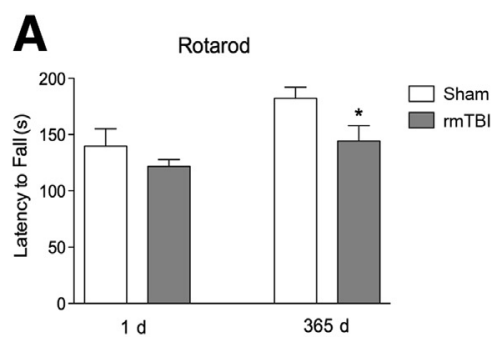

D

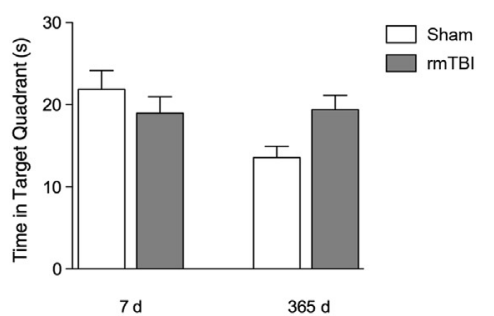

B

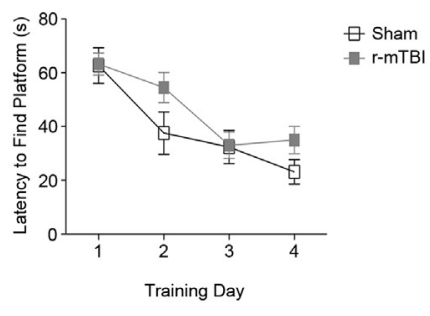

$\mathbf{E}$

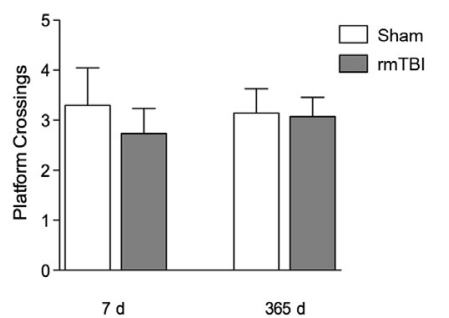

C

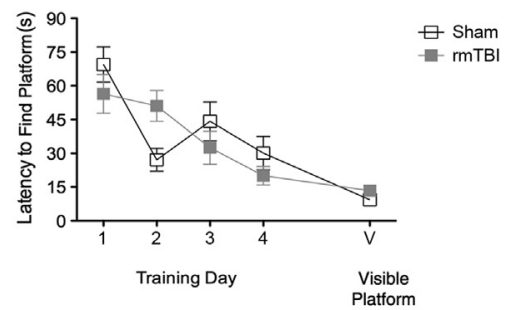

$\mathbf{F}$

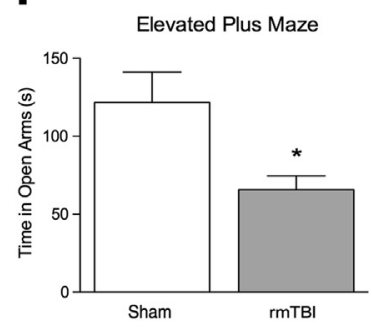

Figure 7 Discrete behavioral changes continue in repeat mild traumatic brain injury (rmTBI) mice up to 365 days after injury. A: The 30 rmTBI (over 6 weeks) mice show delayed impairments on the rotarod test, with significant impairments present 365 days after injury. B and C: The 30 rmTBI mice have no learning impairments in the Morris water maze (MWM) either $\mathbf{7}$ (B) or 365 days after injury (C). D and E: In the probe trial, rmTBI mice show no reductions in the time spent in the target quadrant, or platform crossings. F: The $30 \times$ rmTBI mice display anxiety-like behavior in the elevated plus maze at 365 days after injury. Values are given as means \pm SEM. $n=9$ to 15 per group $(\mathbf{A}-\mathbf{F}) .{ }^{*} P<0.05$ versus sham.

First, we determined if rmTBI altered tau phosphorylation in 3xTg-AD mice. For this purpose, tau phosphorylation was analyzed by Western blot analysis using a panel of specific antitau antibodies that we have previously characterized. ${ }^{22}$ We found no changes in tau phosphorylation state in multiple brain regions, including the cortex (Figure 8), hippocampus, and midbrain (Figure 9).

We also examined radioimmunoprecipitation assay soluble and insoluble pools of $\mathrm{A} \beta_{40}$ by enzyme-linked immunosorbent assay. We found that rmTBI had no effect on $A \beta$ at either time point after injury (Figure 9).

\section{Discussion}

Our aim was to determine the acute effects of a single mTBI, and the chronic effects of rmTBIs on neuronal architecture and the development of brain pathology in mice. We have developed a new model of rmTBI that allows for up to $30 \mathrm{mTBIs}$ without the need for head restraint or surgery. Our model allowed for a highly regulated, reproducible head impact to be delivered directly to the mouse head. LOC is not a necessary component of mTBI in humans; however, its presence in animal models can be useful for grading injury severity, and we optimized our model to select the lowest head deflection depth that caused a minor, but statistically significant, LOC. This gave us a quantifiable outcome measure to indicate that an mTBI had occurred, but with a low enough deflection depth to prevent major structural damage from occurring. This allowed us to scale our model to $30 \mathrm{mTBIs}$, and will allow us to scale up to more human appropriate numbers for future studies. We were able to increase the duration of LOC by increasing the head deflection depth, suggesting that the period of LOC is directly related to the force delivered and rotation of the head after impact. Our model also allows us to ask clinically relevant questions, such as the effect of rmTBI on LOC over time. In a study of sports athletes, it was found that players with a history of three or more concussions were three times more likely to have an incident concussion than those with no concussion history. ${ }^{25}$ In our model, we can determine whether the threshold for LOC is reduced by exposure to earlier mTBI.

\section{The Duration of LOC Remains Constant after rmTBI}

Our experiments demonstrate that 6 weeks of rmTBI do not alter the period of LOC, with all mice remaining unconscious for similar periods of time from week 1 to week 6 . Recently, it was reported that mice exposed to seven rmTBIs have reduced LOC with increased impact number. ${ }^{26}$ The authors of that study report a significant LOC on days 1 and 2, but not on days 3 to 7; however, an examination of the published data shows that the reduction in the difference in LOC between sham and rmTBI mice is because of a combination of an increase in LOC in the sham mice and a reduction in LOC of the rmTBI mice. ${ }^{26}$ Indeed, in our study, we find that on certain days, there is not a significant LOC in rmTBI mice, so to smooth out daily variability, we assessed our LOC data by weekly averages. We find that the period of LOC in the rmTBI mice remained consistent for the 6-week duration of 
A
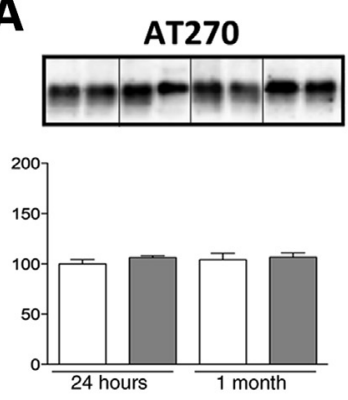

E
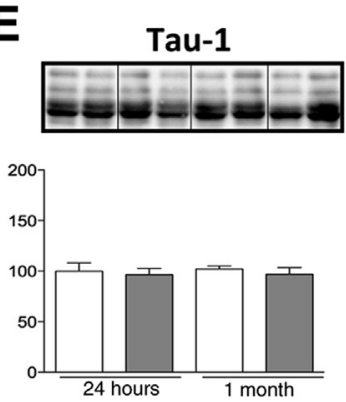

I
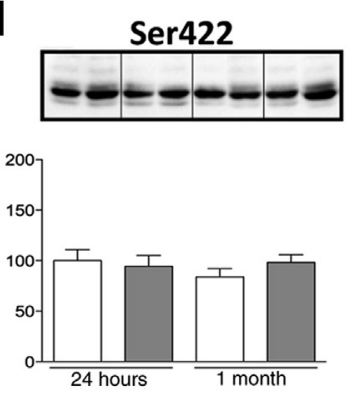

B
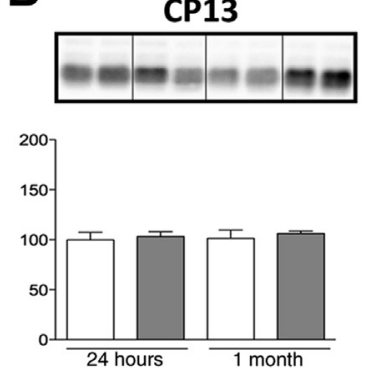

F
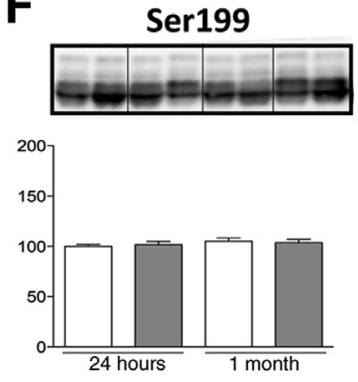

J
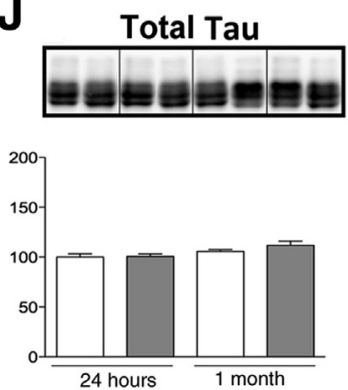

C
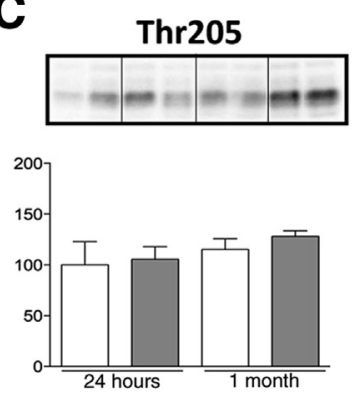

G
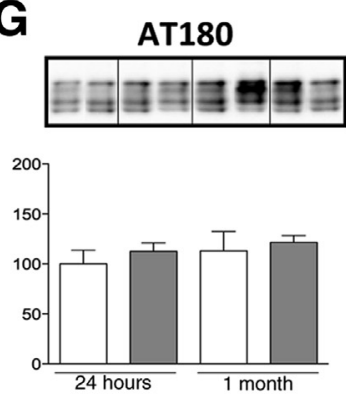

K
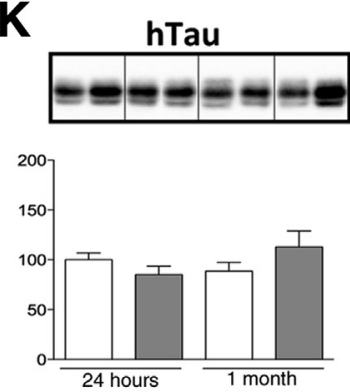

D
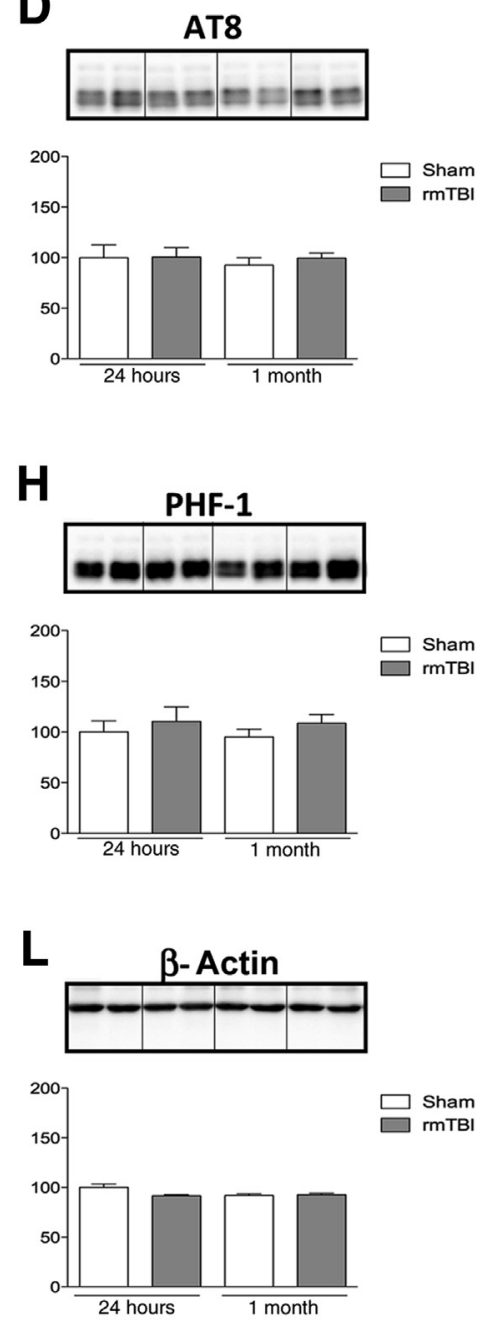

Figure 8 Repeat mild traumatic brain injury (rmTBI) does not alter tau phosphorylation in the cortex of $3 \times \mathrm{Tg}$ mice. $3 \times \mathrm{Tg}$ mice were exposed to 5 mTBIs per week for 4 weeks (20 mTBIs total) and euthanized at 24 hours or 1 month after injury. A-L: Representative Western blots from the cortex extracted in radioimmunoprecipitation assay buffer. The antibody used is indicated above each blot, with quantification directly below. Phospho-epitope levels (A-I) are normalized to total tau (J). Total tau and human tau (hTau; CP27; $\mathbf{J}$ and $\mathbf{K}$, respectively) are normalized to the corresponding $\beta$-actin (L). Densitometric analyses are represented as a percentage of sham. No changes were observed in the cortex of rmTBI mice at either time point. Values are given as means \pm SEM $(\mathbf{A}-\mathbf{L}) \cdot n=5$ to 6 per group $(\mathbf{A}-\mathbf{L})$.

the study. We also find that the period of LOC in the sham mice increased by almost $50 \%$ over the same 6-week period. We interpret this as an effect of repeat isoflurane anesthesia, more than an effect of repetitive exposure to mTBI. It is also possible that as the isoflurane alone is producing a deeper and longer LOC at week 6 versus week 1, it may be masking a habituating effect of rmTBI on LOC. Indeed, if we subtract the LOC because of anesthesia from the combined LOC, we see that the effect of mTBI decreases from 38 seconds in week 1 to 18 seconds in week 6 . The issue of anesthesia and its interaction with $\mathrm{mTBI}$-induced LOC will require future studies, but the introduction of rodent rmTBI models with no anesthesia will help to address these long-standing issues. ${ }^{27}$ It is clear that exposure to previous mTBI does not increase LOC time in later mTBI exposures, and because our model is sensitive to increased impact strength, we conclude that the increased risk of developing incident concussions after prior $\mathrm{mTBI}^{25}$ does not appear to be because of a lowering of threshold by prior mTBI.

\section{Rapid but Temporary Synaptic Loss Occurs after a Single mTBI}

We also report that a single mTBI in mice caused an acute reduction of excitatory synapses, as indicated by a reduction in the number of dendritic spines in multiple regions of the injured brain. We have recently demonstrated that a global decrease in dendritic spine number occurs in mice after a controlled cortical impact injury, ${ }^{18}$ with a $27 \%$ loss of dendritic spines occurring in layer II/III of the ipsilateral cortex, and spine loss in sites far distant from the impact zone, such as the contralateral entorhinal cortex. ${ }^{18}$ Dendritic 
A

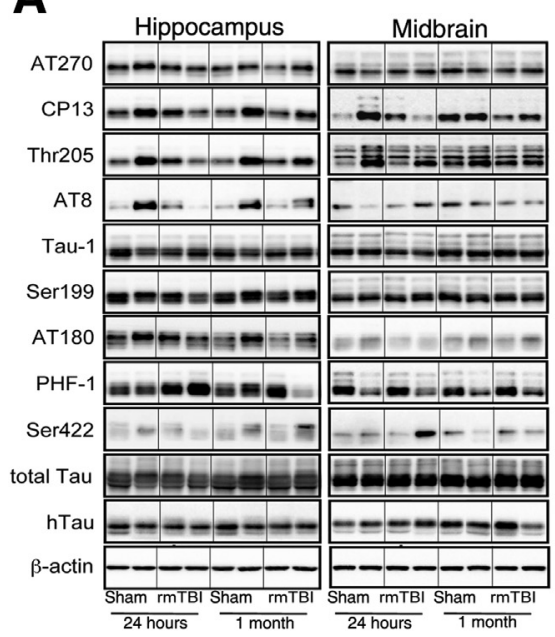

B

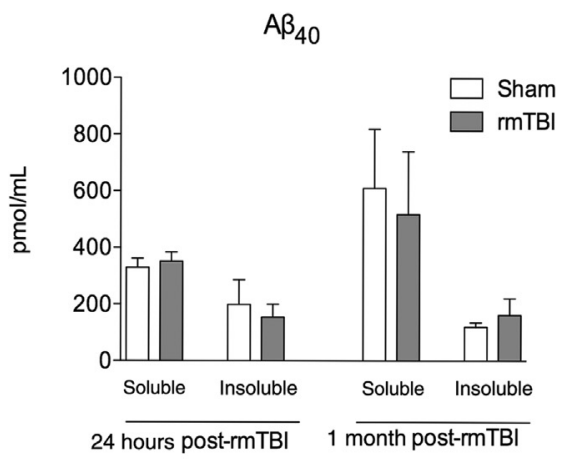

Figure 9 Repeat mild traumatic brain injury (rmTBI) does not alter tau phosphorylation or $A \beta$ accumulation in $3 \times \mathrm{Tg}$ mice. $3 \times \mathrm{Tg}$ mice were exposed to five mTBIs per week for 4 weeks (20 mTBIs total) and euthanized at 24 hours or 1 month after injury. A: Representative images of phosphorylated tau epitopes after rmTBI. No significant changes were observed in either the hippocampus or the midbrain from an average of five to six mice per group. B: Cortical radioimmunoprecipitation assay (soluble) and formic acid (insoluble) $A \beta_{40}$ were quantified by enzymelinked immunosorbent assay. Values are given as means \pm SEM (B). $n=5$ to 6 per group (B). spine loss also occurs after rat lateral fluid percussion injury (FPI) ${ }^{28}$ where in the absence of a lesion there is a $21 \%$ loss in total spines on the AO dendrites of layer II/III cortical neurons 24 hours after injury. ${ }^{28}$ In vitro stretch injury of neurons also causes a prolonged loss of excitatory synaptic transmission. ${ }^{29}$ In the present study, we focused our spine counts on layers II/III of the cortex and report that a single mTBI causes a $13 \%$ loss of spines in the AO dendrites in young male mice, with a greater spine loss occurring after mTBI on the same dendrites in aged male mice. Combined together, these studies of dendritic spines after TBI show that this is a common phenomenon that occurs in a severe TBI model (controlled cortical impact) ${ }^{18,30}$ a moderate TBI model (FPI) ${ }^{28}$ and our mild TBI model. Thus, our work and that of others demonstrate that the loss of dendritic spines is an event that occurs after all severities of TBI and may be one of the common acute events that occur after head trauma, even in the absence of neuronal cell death, axonal injury, or inflammation. The reduction in dendritic spines is a dynamic event after mTBI. Other groups have previously shown that dendritic spines rebound and are increased by 7 days after a midline FPI, ${ }^{28}$ and herein we observe that spine loss is a temporary and spontaneously recoverable phenomenon in our mTBI model with a significant increase in spine numbers at 3 days after injury.

Given that dendritic spine loss occurs after all severities of TBI, we predicted that spine loss would also be a feature of rmTBI. However, when 30 rmTBIs were given over a 6-week period, we found that neurons appear to adapt to rmTBI with no significant differences in dendritic spine numbers between sham and rmTBI mice at 1,60 , or 365 days after injury. We postulated that this was a habituation to the effect of mTBI. To test our hypothesis, we increased the time period between rmTBI from 1 to 7 days, which increased the period of convalescence between rmTBI reinstated dendritic spine loss after the final mTBI. The spine loss in 30 rmTBI mice over 30 weeks was not significantly greater than the loss occurring after a single
mTBI, showing that there is not an additive effect of rmTBI on dendritic spine-even if there is a sufficient period of rest between injuries. One of the mechanisms that control dendritic spine loss after TBI includes calcineurin, a calcium/calmodulin-dependent phosphatase. ${ }^{28,31}$ TBI results in an increase in extracellular glutamate, ${ }^{32-34}$ leading to stimulation of glutamate receptors and activation of synaptic calcium/calmodulin-dependent proteins. ${ }^{35}$ Thus, a transient loss of dendritic spines may be a neuroprotective effect to reduce calcium influx and to allow the neuron to regain calcium homeostasis. The results of the current study lead us to hypothesize that dendritic spine loss after mTBI may not be a detrimental event, but instead may reflect a normal response of the neuron to adapt to the changing environment. This neuroprotective event after mTBI does not happen if repetitive injuries occur without a period of rest and recuperation between head impacts. The chronic consequences of habituation to this response are unclear.

\section{Chronic White Matter Inflammation Is Induced by rmTBI}

Our intent in developing this model of mTBI was to have a model that presented with minimal cell death or neuroinflammation after a few impacts. Although preclinical models of mTBI have been reported by numerous groups, many report serious adverse effects, including skull fracture, extensive white matter axonal injury, and widespread cell death, that would not make these models suitable for scaling up to a greater number of rmTBIs. ${ }^{3-8}$ More recent models have reduced these adverse events, but remain limited in their number of repeat impacts. ${ }^{27,36-41}$ Our model has limited adverse events; however, we do find slowly accumulating white matter damage in the optic tract. Damage to the optic tract occurs concurrently with microglial transformation from ramified microglia to large, bushy microglia. These 
activated microglia can also be found in the lateral geniculate nucleus of the thalamus. The optic nerve and tract have now been shown to be damaged in diverse injury models, including blast injury, ${ }^{42,43}$ rmTBI, ${ }^{38,41,44}$ and FPI, ${ }^{45,46}$ suggesting that the visual system could be studied as an indicator of exposure to trauma. It is unclear why the visual system is susceptible to different types of injury, but the vulnerability of the optic tract to rmTBI may stem from the position of the optic nerve below the brain. The vasculature of the optic nerve is derived from the pial arteries, and it is possible that any swelling of the optic nerve after rmTBI will cause a localized ischemia that may be exacerbating the injury to this nerve. Indeed, disruption of the blood-brain barrier around the optic tract has been reported after FPI and rmTBI. ${ }^{41,46}$ These same studies noted optic nerve damage, a loss of retinal ganglion cells, and functional eye deficits after rmTBI, ${ }^{41,44}$ although the loss of RCG is not reported after FPI. ${ }^{46}$ We did not quantify retinal ganglion cells in our model system.

We also observed that the number of Iba-1-positive cells in the optic tract continued to significantly increase through 60 days after injury. These cells, which were also CD68 positive, presented with a large, bushy morphology. Interestingly, the significant increase in these cells from 1 to 60 days after injury corresponded to a significant reduction in silver staining from 1 to 60 days after injury, suggesting that their presence may be involved in the resolution of axonal injury in these mice. By 365 days after injury, the silver staining abnormalities had resolved, but the number of microglia remained significantly elevated and sporadic bushy microglia remained. These data demonstrate that white matter pathology after rmTBI is chronic, similar to reports from human TBI brains that show that white matter inflammation is a long-lasting consequence of TBI, with activated microglia residing in white matter tracts up to 18 years after TBI in humans, ${ }^{47}$ and 1 year after mTBI in mice. ${ }^{48}$ We have not characterized the functional state of the microglia in the optic tract after rmTBI. Further characterization will be needed to identify which glial phenotypes are expressed in these microglia. We also do not know the underlying condition of the optic tract at 365 days after injury. Axonal degeneration of the optic nerve can occur after rmTBI, ${ }^{41}$ and without further studies, we do not know how chronic inflammation is involved in axonal loss and remyelination.

\section{Persistent Anxiety Phenotype after rmTBI}

Motor impairments and cognitive deficits are commonly reported acutely, subacutely, and chronically after rmTBI, ${ }^{5,26,27,37,48-50}$ and we confirm those findings in our model. Although other groups have reported cognitive deficits in their models, ${ }^{26,36,37}$ we do not see learning or memory deficits acutely or chronically after the final mTBI. This is consistent with the lack of dendritic spine loss in the same mice. Anxiety-like behavior is increasingly being assessed in animal models of rmTBI because of the increased risk of post-traumatic stress disorder. Several groups have demonstrated that injured rmTBI mice spend more time in the open arms at 17 days and 3 months after injury, ${ }^{26}$ at 1 and 6 months after injury, ${ }^{27}$ and at 12 months after injury, ${ }^{48}$ which corresponds to reduced anxiety and increased risk-taking behavior. Herein, we find that rmTBI mice spend less time in the open arms at 365 days after injury, which corresponds to increased anxiety.

Our study shows that extending the interinjury interval can alter the response of dendritic spines to rmTBI, and we believe that a shorter interinjury interval will also affect behavioral outcome measures. Recently, preclinical studies of rmTBI suggest that impacts sustained within vulnerable time periods will amplify brain pathology, ${ }^{51}$ and result in cognitive and behavioral deficits ${ }^{5,36,52}$ up to a year after injury. ${ }^{26,48}$ Conversely, increasing the recovery time between impacts can improve cognitive outcome and attenuate brain pathology after rmTBI. ${ }^{37}$ Future studies on the interinjury interval in our model will determine whether that precipitates a worse outcome after rmTBI.

\section{rmTBI Does Not Induce Amyloid or Tau Pathology in 3xTG-AD Mice}

We introduced the 3xTg-AD mouse model into these experiments to study acute and chronic amyloid and tau changes after rmTBI. CTE is primarily known as a tauopathy; however, because $52 \%$ of 114 neuropathologically confirmed CTE brains also demonstrate concomitant $\mathrm{A} \beta$ plaque deposition, ${ }^{11}$ we wanted to introduce a mouse model that has the ability to produce both amyloid and tau pathology. The $3 \mathrm{xTg}$-AD mouse overexpresses mutant human APP and tau, leading to amyloid plaques and tau tangles in the brain. ${ }^{16}$ In $\mathrm{AD}$, the formation of neurofibrillary tangles is preceded by the accumulation of hyperphosphorylated tau. ${ }^{53}$ However, although hyperphosphorylation of tau seems to be a prerequisite for tau pathogenesis, ${ }^{54}$ it does not necessarily lead to tangle formation, as exemplified by tau hyperphosphorylation during early development. ${ }^{55}$ Which form of tau is actually pathogenic is still an ongoing debate. ${ }^{5,57}$ Nevertheless, phosphorylation is routinely examined in animal models of $\mathrm{AD}$ as a first step to examine tau pathology, because there is no animal model that develops tangles without tau hyperphosphorylation.

In our study, we found no changes in tau phosphorylation in multiple brain regions, including the cortex, hippocampus, or thalamus/striatum. However, multiple groups, including ours, have reported acute increases in phosphorylated (phospho-tau) epitopes after a single TBI, including after controlled cortical impact in tau transgenic mice ${ }^{58,59}$ and blast injury in wild-type mice. ${ }^{60}$ Chronic hyperphosphorylation of tau has been reported at a single tau epitope in APP transgenic mice at 3 months after 
closed-head injury. ${ }^{61}$ Those reports involve a single TBI, are limited in the number of phospho-epitopes they describe, and are using animal models of higher severity than the model we describe herein. Acute increases in phospho-tau after rmTBI have been reported in wild-type mice at 12,24 , and 48 hours after two mTBIs, ${ }^{38}$ but again this mouse model is more severe than our rmTBI model, with more extensive white matter damage through the corpus callosum. There has been one report of accelerated hyperphosphorylated tau staining, accompanied by an increase in Gallyas silver staining, in aged human tau mice exposed to $5 \mathrm{rmTBIs}$ over a 9-day period and euthanized 21 days after the final injury. ${ }^{12}$ However, we found no evidence of increased phospho-tau at either 1 or 30 days after injury in our aged $3 \times T g-A D$ mice. There are differences between our study and the study by Mouzon et al. ${ }^{49}$ We used a different transgenic mouse model ( $3 \times \mathrm{Tg}-\mathrm{AD}$ has a single mutant human tau isoform, but the human tau mouse has all six human tau isoforms), and the trauma model used in the human tau study appears to be more severe than our model, with traumatic axonal injury evidenced by APP accumulation in the corpus callosum in their model. We did not see any APP accumulation in our mice. Because the acute increases in phospho-tau appear to occur primarily in traumatically injured axons, ${ }^{58,59}$ this difference between the level of axonal injury might explain why we do not see changes in phospho-tau in our mice. This rationale also holds true for the lack of an increase in $A \beta$, or a shift in solubility of $\mathrm{A} \beta$, after $30 \mathrm{rmTBIs}$. We, and others, have previously shown that the abnormal production of $A \beta$ after TBI occurs at sites of axonal injury, ${ }^{23,59,62}$ and in the absence of APP-positive varicosities, it is unlikely that $\mathrm{A} \beta$ is being produced in higher amounts in our $3 \times \mathrm{Tg}-\mathrm{AD}$ mice.

\section{Conclusions}

We have described a new model of rmTBI that can be scaled to mimic the numbers of rmTBIs that have been reported in professional athletes. We find that the brain has complex reactions to a repeat versus a single mTBI with no adaptation to LOC after impact, but with adaptation occurring because of the loss of dendritic spines. Dendritic spine loss can be reinstated if the number of impacts is spaced further apart, suggesting that the temporary loss of spines is a normal response to mTBI that is lost when the interinjury interval is too short. Repeat strain on white matter pathways can result in prolonged inflammation that continues for months after the final mTBI, confirming previous groups' assertions that the optic system may be vulnerable to rmTBI. ${ }^{41,44}$ The relationship between rmTBI and the development of tauopathy remains complex, and herein we report no evidence of phospho-tau or $A \beta$ accumulation in $3 \times \mathrm{Tg}-\mathrm{AD}$ mice after rmTBI. This model will be useful for the study of synaptic loss after mTBI and rmTBI as a trigger of white matter pathology.

\section{Acknowledgment}

We thank Dr. Peter Davies (Litwin-Zucker Research Center for The Study of Alzheimer Disease and Memory Disorders, Manhasset, NY) for multiple anti-tau antibodies.

\section{References}

1. Talavage TM, Nauman EA, Breedlove EL, Yoruk U, Dye AE, Morigaki KE, Feuer H, Leverenz LJ: Functionally-detected cognitive impairment in high school football players without clinicallydiagnosed concussion. J Neurotrauma 2014, 31:327-338

2. Angoa-Perez M, Kane MJ, Briggs DI, Herrera-Mundo N, Viano DC, Kuhn DM: Animal models of sports-related head injury: bridging the gap between pre-clinical research and clinical reality. J Neurochem 2014, 129:916-931

3. Creed JA, Dileonardi AM, Fox DP, Tessler AR, Raghupathi R: Concussive brain trauma in the mouse results in acute cognitive deficits and sustained impairment of axonal function. J Neurotrauma 2011, 28:547-563

4. Hamberger A, Viano DC, Saljo A, Bolouri H: Concussion in professional football: morphology of brain injuries in the NFL concussion model-part 16. Neurosurgery 2009, 64:1174-1182

5. Kane MJ, Angoa-Perez M, Briggs DI, Viano DC, Kreipke CW, Kuhn DM: A mouse model of human repetitive mild traumatic brain injury. J Neurosci Methods 2012, 203:41-49

6. Laurer HL, Bareyre FM, Lee VM, Trojanowski JQ, Longhi L, Hoover R, Saatman KE, Raghupathi R, Hoshino S, Grady MS, McIntosh TK: Mild head injury increasing the brain's vulnerability to a second concussive impact. J Neurosurg 2001, 95:859-870

7. Prins ML, Hales A, Reger M, Giza CC, Hovda DA: Repeat traumatic brain injury in the juvenile rat is associated with increased axonal injury and cognitive impairments. Dev Neurosci 2010, 32:510-518

8. Tang YP, Noda Y, Hasegawa T, Nabeshima T: A concussive-like brain injury model in mice (II): selective neuronal loss in the cortex and hippocampus. J Neurotrauma 1997, 14:863-873

9. Corsellis JA, Bruton CJ, Freeman-Browne D: The aftermath of boxing. Psychol Med 1973, 3:270-303

10. McKee AC, Cantu RC, Nowinski CJ, Hedley-Whyte ET, Gavett BE, Budson AE, Santini VE, Lee HS, Kubilus CA, Stern RA: Chronic traumatic encephalopathy in athletes: progressive tauopathy after repetitive head injury. J Neuropathol Exp Neurol 2009, 68:709-735

11. Stein TD, Montenigro PH, Alvarez VE, Xia W, Crary JF, Tripodis Y, Daneshvar DH, Mez J, Solomon T, Meng G, Kubilus CA, Cormier KA, Meng S, Babcock K, Kiernan P, Murphy L, Nowinski CJ, Martin B, Dixon D, Stern RA, Cantu RC, Kowall NW, McKee AC: Beta-amyloid deposition in chronic traumatic encephalopathy. Acta Neuropathol 2015, 130:21-34

12. Ojo JO, Mouzon B, Greenberg MB, Bachmeier C, Mullan M, Crawford F: Repetitive mild traumatic brain injury augments tau pathology and glial activation in aged hTau mice. J Neuropathol Exp Neurol 2013, 72:137-151

13. Committee for the Update of the Guide for the Care and Use of Laboratory Animals; National Research Council: Guide for the Care and Use of Laboratory Animals. ed 8. Washington, DC, National Academies Press, 2011

14. Cernak I, Chang T, Ahmed FA, Cruz MI, Vink R, Stoica B, Faden AI: Pathophysiological response to experimental diffuse brain trauma differs as a function of developmental age. Dev Neurosci 2010, 32:442-453

15. Cernak I, Vink R, Zapple DN, Cruz MI, Ahmed F, Chang T, Fricke ST, Faden AI: The pathobiology of moderate diffuse traumatic brain injury as identified using a new experimental model of injury in rats. Neurobiol Dis 2004, 17:29-43 
16. Oddo S, Caccamo A, Shepherd JD, Murphy MP, Golde TE, Kayed R, Metherate R, Mattson MP, Akbari Y, LaFerla FM: Triple-transgenic model of Alzheimer's disease with plaques and tangles: intracellular Abeta and synaptic dysfunction. Neuron 2003, 39:409-421

17. Hirata-Fukae C, Li HF, Hoe HS, Gray AJ, Minami SS, Hamada K, Niikura T, Hua F, Tsukagoshi-Nagai H, Horikoshi-Sakuraba Y, Mughal M, Rebeck GW, LaFerla FM, Mattson MP, Iwata N, Saido TC, Klein WL, Duff KE, Aisen PS, Matsuoka Y: Females exhibit more extensive amyloid, but not tau, pathology in an Alzheimer transgenic model. Brain Res 2008, 1216:92-103

18. Winston CN, Chellappa D, Wilkins T, Barton DJ, Washington PM, Loane DJ, Zapple DN, Burns MP: Controlled cortical impact results in an extensive loss of dendritic spines that is not mediated by injuryinduced amyloid-beta accumulation. J Neurotrauma 2013, 30: 1966-1972

19. de Olmos JS, Beltramino CA, de Olmos de Lorenzo S: Use of an amino-cupric-silver technique for the detection of early and semiacute neuronal degeneration caused by neurotoxicants, hypoxia, and physical trauma. Neurotoxicol Teratol 1994, 16:545-561

20. Kumar A, Stoica BA, Sabirzhanov B, Burns MP, Faden AI, Loane DJ: Traumatic brain injury in aged animals increases lesion size and chronically alters microglial/macrophage classical and alternative activation states. Neurobiol Aging 2013, 34:1397-1411

21. Planel E, Richter KE, Nolan CE, Finley JE, Liu L, Wen Y, Krishnamurthy P, Herman M, Wang L, Schachter JB, Nelson RB, Lau LF, Duff KE: Anesthesia leads to tau hyperphosphorylation through inhibition of phosphatase activity by hypothermia. J Neurosci 2007, 27:3090-3097

22. Petry FR, Pelletier J, Bretteville A, Morin F, Calon F, Hebert SS, Whittington RA, Planel E: Specificity of anti-tau antibodies when analyzing mice models of Alzheimer's disease: problems and solutions. PLoS One 2014, 9:e94251

23. Washington PM, Morffy N, Parsadanian M, Zapple DN, Burns MP: Experimental traumatic brain injury induces rapid aggregation and oligomerization of amyloid-beta in an Alzheimer's disease mouse model. J Neurotrauma 2014, 31:125-134

24. Washington PM, Forcelli PA, Wilkins T, Zapple DN, Parsadanian M, Burns MP: The effect of injury severity on behavior: a phenotypic study of cognitive and emotional deficits after mild, moderate, and severe controlled cortical impact injury in mice. J Neurotrauma 2012 , 29:2283-2296

25. Guskiewicz KM, McCrea M, Marshall SW, Cantu RC, Randolph C, Barr W, Onate JA, Kelly JP: Cumulative effects associated with recurrent concussion in collegiate football players: the NCAA Concussion Study. JAMA 2003, 290:2549-2555

26. Mannix R, Berglass J, Berkner J, Moleus P, Qiu J, Andrews N, Gunner G, Berglass L, Jantzie LL, Robinson S, Meehan WP 3rd: Chronic gliosis and behavioral deficits in mice following repetitive mild traumatic brain injury. J Neurosurg 2014, 121:1342-1350

27. Petraglia AL, Plog BA, Dayawansa S, Chen M, Dashnaw ML, Czerniecka K, Walker CT, Viterise T, Hyrien O, Iliff JJ, Deane R, Nedergaard M, Huang JH: The spectrum of neurobehavioral sequelae after repetitive mild traumatic brain injury: a novel mouse model of chronic traumatic encephalopathy. J Neurotrauma 2014, 31:1211-1224

28. Campbell JN, Register D, Churn SB: Traumatic brain injury causes an FK506-sensitive loss and an overgrowth of dendritic spines in rat forebrain. J Neurotrauma 2012, 29:201-217

29. Goforth PB, Ren J, Schwartz BS, Satin LS: Excitatory synaptic transmission and network activity are depressed following mechanical injury in cortical neurons. J Neurophysiol 2011, 105: $2350-2363$

30. Gao X, Deng P, Xu ZC, Chen J: Moderate traumatic brain injury causes acute dendritic and synaptic degeneration in the hippocampal dentate gyrus. PLoS One 2011, 6:e24566

31. Campbell JN, Low B, Kurz JE, Patel SS, Young MT, Churn SB: Mechanisms of dendritic spine remodeling in a rat model of traumatic brain injury. J Neurotrauma 2012, 29:218-234
32. Bullock R, Zauner A, Woodward JJ, Myseros J, Choi SC, Ward JD, Marmarou A, Young HF: Factors affecting excitatory amino acid release following severe human head injury. J Neurosurg 1998, 89: 507-518

33. Vespa P, Prins M, Ronne-Engstrom E, Caron M, Shalmon E, Hovda DA, Martin NA, Becker DP: Increase in extracellular glutamate caused by reduced cerebral perfusion pressure and seizures after human traumatic brain injury: a microdialysis study. J Neurosurg 1998, 89:971-982

34. Folkersma H, Foster Dingley JC, van Berckel BN, Rozemuller A, Boellaard R, Huisman MC, Lammertsma AA, Vandertop WP, Molthoff CF: Increased cerebral (R)-[(11)C]PK11195 uptake and glutamate release in a rat model of traumatic brain injury: a longitudinal pilot study. J Neuroinflammation 2011, 8:67

35. Atkins CM, Chen S, Alonso OF, Dietrich WD, Hu BR: Activation of calcium/calmodulin-dependent protein kinases after traumatic brain injury. J Cereb Blood Flow Metab 2006, 26:1507-1518

36. Luo J, Nguyen A, Villeda S, Zhang H, Ding Z, Lindsey D, Bieri G, Castellano JM, Beaupre GS, Wyss-Coray T: Long-term cognitive impairments and pathological alterations in a mouse model of repetitive mild traumatic brain injury. Front Neurol 2014, 5:12

37. Meehan WP 3rd, Zhang J, Mannix R, Whalen MJ: Increasing recovery time between injuries improves cognitive outcome after repetitive mild concussive brain injuries in mice. Neurosurgery 2012, $71: 885-891$

38. Namjoshi DR, Cheng WH, McInnes KA, Martens KM, Carr M, Wilkinson A, Fan J, Robert J, Hayat A, Cripton PA, Wellington CL: Merging pathology with biomechanics using CHIMERA (ClosedHead Impact Model of Engineered Rotational Acceleration): a novel, surgery-free model of traumatic brain injury. Mol Neurodegener 2014, 9:55

39. Shitaka Y, Tran HT, Bennett RE, Sanchez L, Levy MA, Dikranian K, Brody DL: Repetitive closed-skull traumatic brain injury in mice causes persistent multifocal axonal injury and microglial reactivity. J Neuropathol Exp Neurol 2011, 70:551-567

40. Weil ZM, Gaier KR, Karelina K: Injury timing alters metabolic, inflammatory and functional outcomes following repeated mild traumatic brain injury. Neurobiol Dis 2014, 70:108-116

41. Xu L, Nguyen JV, Lehar M, Menon A, Rha E, Arena J, Ryu J, Marsh-Armstrong N, Marmarou CR, Koliatsos VE: Repetitive mild traumatic brain injury with impact acceleration in the mouse: multifocal axonopathy, neuroinflammation, and neurodegeneration in the visual system. Exp Neurol 2015, 273: $168-176$

42. Koliatsos VE, Cernak I, Xu L, Song Y, Savonenko A, Crain BJ, Eberhart CG, Frangakis CE, Melnikova T, Kim H, Lee D: A mouse model of blast injury to brain: initial pathological, neuropathological, and behavioral characterization. J Neuropathol Exp Neurol 2011, 70: 399-416

43. Mohan K, Kecova H, Hernandez-Merino E, Kardon RH, Harper MM: Retinal ganglion cell damage in an experimental rodent model of blast-mediated traumatic brain injury. Invest Ophthalmol Vis Sci 2013, 54:3440-3450

44. Tzekov R, Quezada A, Gautier M, Biggins D, Frances C, Mouzon B, Jamison J, Mullan M, Crawford F: Repetitive mild traumatic brain injury causes optic nerve and retinal damage in a mouse model. J Neuropathol Exp Neurol 2014, 73:345-361

45. Wang J, Fox MA, Povlishock JT: Diffuse traumatic axonal injury in the optic nerve does not elicit retinal ganglion cell loss. J Neuropathol Exp Neurol 2013, 72:768-781

46. Wang J, Hamm RJ, Povlishock JT: Traumatic axonal injury in the optic nerve: evidence for axonal swelling, disconnection, dieback, and reorganization. J Neurotrauma 2011, 28:1185-1198

47. Johnson VE, Stewart JE, Begbie FD, Trojanowski JQ, Smith DH, Stewart W: Inflammation and white matter degeneration persist for years after a single traumatic brain injury. Brain 2013, 136:28-42 
48. Mouzon BC, Bachmeier C, Ferro A, Ojo JO, Crynen G, Acker CM, Davies P, Mullan M, Stewart W, Crawford F: Chronic neuropathological and neurobehavioral changes in a repetitive mild traumatic brain injury model. Ann Neurol 2014, 75:241-254

49. Mouzon B, Chaytow H, Crynen G, Bachmeier C, Stewart J, Mullan M, Stewart W, Crawford F: Repetitive mild traumatic brain injury in a mouse model produces learning and memory deficits accompanied by histological changes. J Neurotrauma 2012, 29: $2761-2773$

50. Aungst SL, Kabadi SV, Thompson SM, Stoica BA, Faden AI: Repeated mild traumatic brain injury causes chronic neuroinflammation, changes in hippocampal synaptic plasticity, and associated cognitive deficits. J Cereb Blood Flow Metab 2014, 34: $1223-1232$

51. Bolton AN, Saatman KE: Regional neurodegeneration and gliosis are amplified by mild traumatic brain injury repeated at 24-hour intervals. J Neuropathol Exp Neurol 2014, 73:933-947

52. Longhi L, Saatman KE, Fujimoto S, Raghupathi R, Meaney DF, Davis J, McMillan BSA, Conte V, Laurer HL, Stein S, Stocchetti N, McIntosh TK: Temporal window of vulnerability to repetitive experimental concussive brain injury. Neurosurgery 2005, 56: 364-374. discussion 374

53. Bancher C, Brunner C, Lassmann H, Budka H, Jellinger K, Wiche G, Seitelberger F, Grundke-Iqbal I, Iqbal K, Wisniewski HM: Accumulation of abnormally phosphorylated tau precedes the formation of neurofibrillary tangles in Alzheimer's disease. Brain Res 1989, 477: 90-99

54. Alonso AC, Zaidi T, Novak M, Grundke-Iqbal I, Iqbal K: Hyperphosphorylation induces self-assembly of tau into tangles of paired helical filaments/straight filaments. Proc Natl Acad Sci U S A 2001, 98:6923-6928

55. Brion JP, Smith C, Couck AM, Gallo JM, Anderton BH: Developmental changes in tau phosphorylation: fetal tau is transiently phosphorylated in a manner similar to paired helical filament-tau characteristic of Alzheimer's disease. J Neurochem 1993, 61: 2071-2080

56. Bretteville A, Planel E: Tau aggregates: toxic, inert, or protective species? J Alzheimers Dis 2008, 14:431-436

57. Duff K, Planel E: Untangling memory deficits. Nat Med 2005, 11: 826-827

58. Washington PM, Villapol S, Burns MP: Polypathology and dementia after brain trauma: does brain injury trigger distinct neurodegenerative diseases, or should they be classified together as traumatic encephalopathy? Exp Neurol 2015, 275(Pt 3): $381-388$

59. Tran HT, LaFerla FM, Holtzman DM, Brody DL: Controlled cortical impact traumatic brain injury in $3 \times \mathrm{Tg}-\mathrm{AD}$ mice causes acute intraaxonal amyloid-beta accumulation and independently accelerates the development of tau abnormalities. J Neurosci 2011, 31: 9513-9525

60. Goldstein LE, Fisher AM, Tagge CA, Zhang XL, Velisek L, Sullivan JA, Upreti C, Kracht JM, Ericsson M, Wojnarowicz MW, Goletiani CJ, Maglakelidze GM, Casey N, Moncaster JA, Minaeva O, Moir RD, Nowinski CJ, Stern RA, Cantu RC, Geiling J, Blusztajn JK, Wolozin BL, Ikezu T, Stein TD, Budson AE, Kowall NW, Chargin D, Sharon A, Saman S, Hall GF, Moss WC, Cleveland RO, Tanzi RE, Stanton PK, McKee AC: Chronic traumatic encephalopathy in blast-exposed military veterans and a blast neurotrauma mouse model. Sci Transl Med 2012, 4:134ra60

61. Laskowitz DT, Song P, Wang H, Mace B, Sullivan PM, Vitek MP, Dawson HN: Traumatic brain injury exacerbates neurodegenerative pathology: improvement with an apolipoprotein E-based therapeutic. J Neurotrauma 2010, 27:1983-1995

62. Uryu K, Chen XH, Martinez D, Browne KD, Johnson VE, Graham DI, Lee VM, Trojanowski JQ, Smith DH: Multiple proteins implicated in neurodegenerative diseases accumulate in axons after brain trauma in humans. Exp Neurol 2007, 208: $185-192$ 